Sädhanā, Vol. 12, Part 3, March 1988, pp, 251-288. (C) Printed in India.

\title{
ISRO spacecraft technology evolution
}

\author{
K KASTURIRANGAN ${ }^{1}$ and $\mathrm{K}$ R SRIDHARAMURTHY ${ }^{2}$ \\ ${ }^{1}$ ISRO Satellite Centre, Airport Road, Vimanapura P O, Bangalore \\ 560017 , India \\ ${ }^{2}$ ISRO Headquarters, Cauvery Bhavan, Kempegowda Road, Banga- \\ lore 560009 , India
}

\begin{abstract}
Evolutionary trends in the technologies related to Indian Space Research Organisation (ISRO) satellites, both past and present, are outlined. The issues related to the developmental complexities of different spacecraft subsystems are discussed in the context of the needs of the current generation operational spacecraft like the Indian Remote Sensing Satellite (IRS) and the Indian National Satellite (INSAT) II. Considerations pertinent to reliability and long-life requirements, crucial to operational satellites, are also highlighted.
\end{abstract}

Keywords. Indian space programme; satellites; operational systems; technology and development; remote sensing; communication.

\section{Introduction}

The growth and evolution of satellite technology in the Indian Space Research Organisation (ISRO) since the inception of related activities in the early seventies was a step-by-step process. During the initial step, which can be termed the learning phase, the basics of the technology were learnt in the process of actually designing, building and operating the satellite Aryabhata (Rao \& Kasturirangan 1979). During the next step, which can be characterized as experimental, missions like Bhaskara (Kasturirangan 1985) and APPLE (Ariane Passenger Payload Experiment) (Vasagam \& Shrivastava 1983) were conceived and executed to gain experience in the conduct of a space mission on an end-to-end basis, in respect of specific application goals in remote sensing, meteorology and communications. Essential methodologies like characterization and design of the remote sensing payloads and the associated definition of spacecraft platforms, three-axis stabilization as well as orbit-raising and on-orbit operations for geosynchronous missions were learnt during this phase. The third step involving the design and development of operational satellites is currently under way. The Indian Remote Sensing Satellite (IRS-1) represents the first in a series of remote sensing satellites (Navalgund \& Kasturirangan 1983) capable of providing operational services for 
resource survey and monitoring. IRS-1 is slated for launch towards the first quarter of 1988. In the case of communications and meteorology, the indigenously developed Indian National Satellite (INSAT) II (Rao \& Ramachandran 1987; Rao et al 1987) represents the second generation INSAT satellites with augmented capacity and improved capabilities, vis-a-vis, the presently bought out INSAT I satellites (Dhawan et al 1979). INSAT II satellites are planned to replace the present INSAT I series in the 1990's. A series of $150 \mathrm{~kg}$ class satellites known as Stretched Rohini Satellite Series (SROSS) (Rao et al 1982) are also presently under development for the conduct of astronomy and aeronomy experiments as well as new and novel application-oriented missions.

In this paper, we propose to trace the evolution of the different technologies related to the ISRO satellite missions, in the context of increasing demands on the performance capabilities, sophistication and reliability of the current IRS-1 and INSAT II operational spacecraft under development.

\section{Systemic aspects of spacecraft configuration}

Central to the definition of a spacecraft is the specification of a mission goal or a set of mission goals related usually to the areas of science, applications or technology. Once the mission goal is laid down, it is possible to identify a set of interactive technical elements that include on one side a spacecraft carrying a payload or a set of payloads appropriate to the mission and a compatible launch vehicle system for placing the satellite in a pre-selected orbit, and on the other side, a network of ground-based telemetry, telecommand and tracking systems that serve to receive the data and exercise control over the spacecraft in its orbital phase. The mission normally concludes with a set of activities involving processing, analysis and interpretation of the data obtained from the experiments.

Once the orbit, the basic payload instrumentation, and the mission duration are defined, it is possible to assess the first level requirements of attitude/orbit control and electrical power needed for the payloads and the other supporting spacecraft subsystems. The attitude/orbit control enables the orientation of the payloads, and other elements having directional properties (such as the antenna), in the requisite directions and helps maintain the orbital parameters within allowable limits. The other important supporting subsystems of the satellite include the structure for providing mechanical support and rigidity to the different electronic and electro-mechanical elements, a thermal-control system for maintaining the temperature of different subsystems within allowable limits, downlink telemetry to process the data gathered by the satellite and transmit the same to the ground station and an uplink that performs the task of sending commands for exercising the satellite in different operating modes while in orbit.

The overall sizing of the spacecraft with respect to its weight and size is carried out at this juncture with due consideration to the constraints imposed by the launch vehicle and the environment. The constraints from the launch vehicle side include the extent of the available volume within the shroud and the total allowable weight for achieving the desired orbit. The environmental factors include the launch stresses, the micro-gravity, the ultra-high vacuum of space and the particulate and ultra-violet radiations. 
The final configuration of a spacecraft is arrived at by a series of iterations that ensure compatibility between the spacecraft, the rocket and the ground systems on one hand and between the different subsystems of the spacecraft on the other. Some of the major elements of this iterative procedure leading to the spacecraft configuration definition are illustrated in figure 1.

The development and improvement of satellite technology has thus been a continuing endeavour dictated by increasing demands on the performance capabiity of the satellites in terms of their higher capacity and longer life times.

\section{Evolution of technologies of subsystems}

As mentioned earlier, a satellite is the product of a variety of engineering disciplines. Even though these disciplines have been brought to bear on the

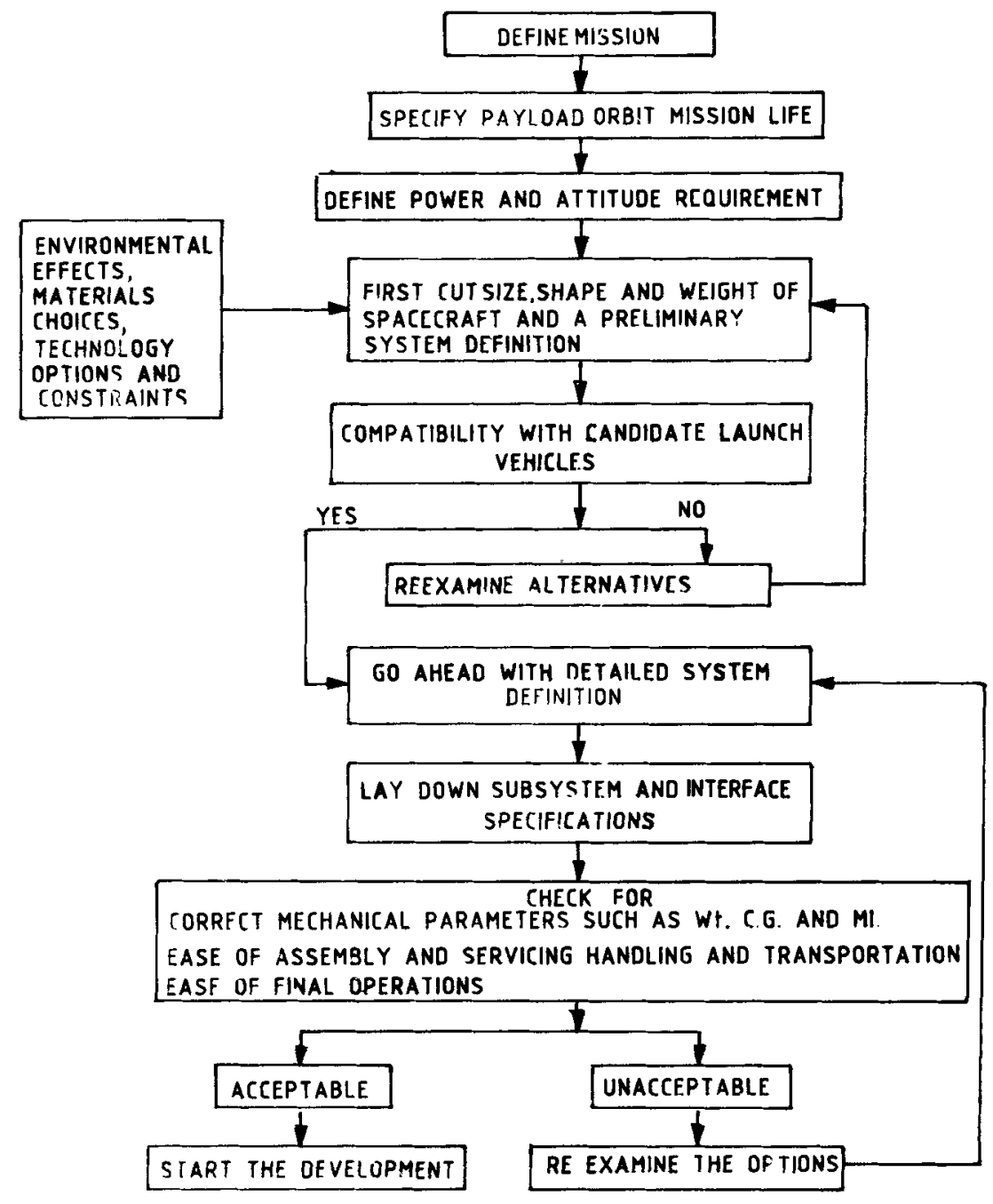

Figure 1. Iterative procedure leading to definition of spacecraft configuration. 
realization of a number of conventional terrestrial systems, what distinguishes the application of these engineering principles to a space system is the need to realize systems that could operate unattended and with a high degree of reliability in the hostile environment of space. The other and equally improtant aspect is to make the systems lightweight, low-power consuming and miniature, calling for a high degree of design optimization. In the following few pages, the evolution of the technologies of different satellite subsystems towards a higher level of complexity and sophistication is dealt with keeping the above considerations in mind.

\subsection{Structure}

The main function of the structure is to safely house all the subsystems and provide adequate shielding against the hostile environment of space. It should have the ability to withstand environmental loads arising from ground handling, transportation, launch and orbit phases. Evolving an efficient and optimum structure (Adams 1966) encompasses three types of activities, viz., design, analysis and testing. There is a strong interaction among these three elements leading to the realization of a structure.

3.1a Design considerations: The criticality of flight and inorbit loads for design, will vary depending on the needs like stiffness requirements, alignment needs and resistance to thermal distortions. For small spacecraft, the design is generally strength-based. In most of the medium and large spacecraft, stiffness requirements dominate as in the case of IRS where the fundamental frequencies in longitudinal and lateral directions should be kept around 30 and $15 \mathrm{~Hz}$, respectively, to avoid strong coupling between launch vehicle and satellite dynamics. Similarly, an acoustic environment becomes important for structural elements like panels with large area to mass ratios like those in IRS and INSAT.

The design of a satellite structure becomes more complex as its size increases due to the interactions involved with other systems. Interaction between the satellite and the launch vehicle is one area of concern when the size of the satellite increases. The loads on a satellite cannot be determined precisely before a dynamic-coupled analysis of launch vehicle and satellite is carried out. This information is also necessary for generating realistic test specifications. Interaction of structural design with that of other subsystems of the satellite also becomes progressively more and more important as the size becomes larger, making increased demands on design complexity. Control system and structure interaction is an area that requires considerable attention. This interaction arises when structural and control frequencies overlap. For example, the INSAT satellite incorporates large panels, whose structural responses could result in some amount of such interaction and this has to be taken into account in control system design. Larger sizes of satellites would involve stronger interaction, and structure or control system design cannot be handled in isolation as is shown in figure 2. Another potential area of interaction is that between thermal and structural systems. Traditional approaches of thermal management as those employed in Aryabhata and Bhaskara, involve calculation of temperatures at various points in the satellite using inter-element radiation and conduction with external and internal loads. These do not suffice for larger systems and we need to integrate this with structural 


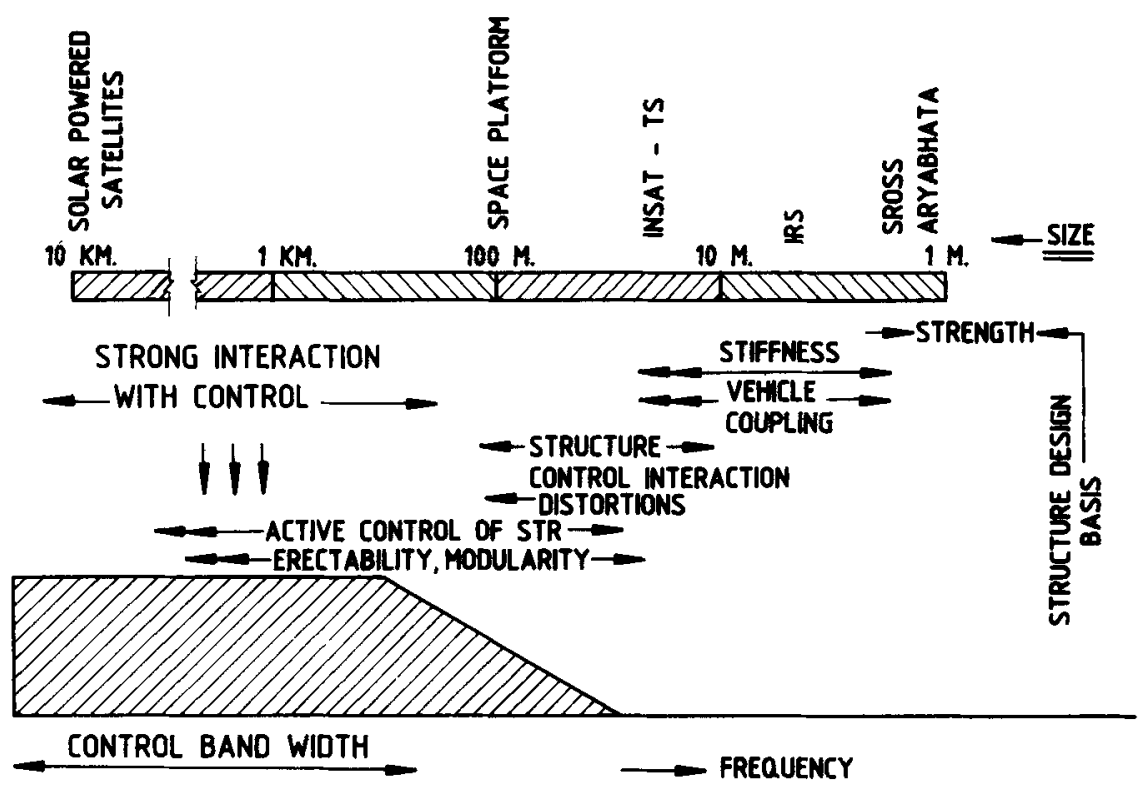

Figure 2. Design considerations of structure in relation to its size.

responses due to view factors affecting temperature distribution. All these factors contribute to making the satellite structural design a highly complex and iterative exercise.

Material selection and fabrication processes contribute primarily to realizing design goals. From Aryabhata with a structural mass of $30 \%$ of the total mass to INSAT II TS (TS-test satellite) with an estimated mass of $7.5 \%$, there has been a steady decrease in the proportional structural mass of ISRO spacecraft. With the use of conventional metals like aluminium, mass reduction could not be continuously improved. The considerable weight reduction in the recent ISRO spacecraft like IRS has come about with the increasing substitution of metal honeycomb for structural elements in place of machined solid elements. This is reflected in figure 3.

Several process and fabrication related problems have to be solved in using honeycomb sandwiches. These include honeycomb-sandwich bonding technology, optimization of process parameters, quality control procedures including nondestructive testing (NDT) and use of lighter cores and adhesives with stricter fabrication tolerances. In addition, special attention has been paid to load transferring mechanisms in honeycomb sandwiches, namely, in insert design and in the use of adhesives of lighter weight. For instance, reduction of weight from $15 \mathrm{gm}$ per insert in APPLE to $6.8 \mathrm{gm}$ per insert in IRS, has been due to these efforts. In assuring the quality of honeycomb and composite components, appropriate NDT techniques such as ultrasonic bond testing, laser holography and acoustic emission have been pressed into service.

Concerted technology development efforts are presently under way for further savings in structural mass in a spacecraft through the use of materials like CFRP, magnesium alloys, aluminium-lithium alloys and beryllium for various structural components. 


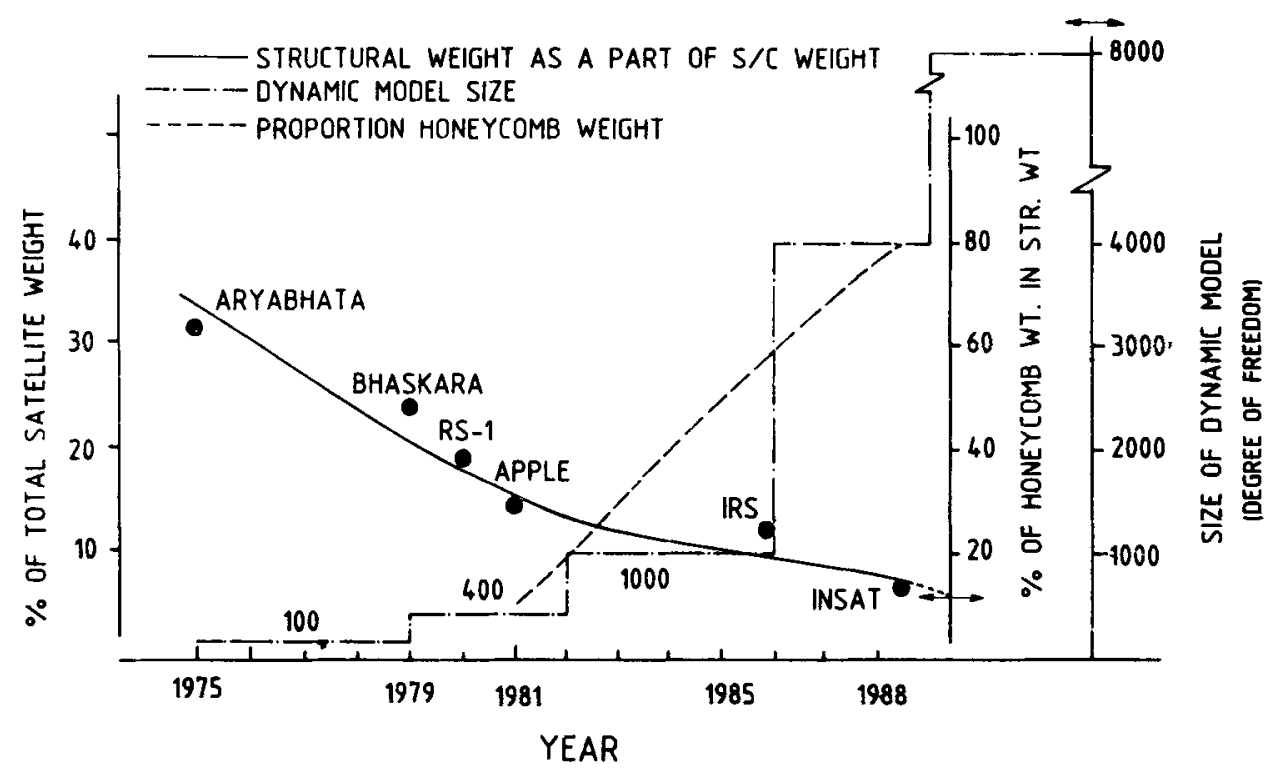

Figure 3. Optimization trends in structures of Indian spacecraft. ( $\longleftrightarrow$ indicates state of art).

3.1b Structural testing: A changing trend in testing of satellites is noticed in the efforts to simulate flight environment as closely as possible. For Aryabhata, only static and sinusoidal dynamic tests were carried out. With a sweep rate of a quarter octave per minute, the dynamic test programme had a high degree of conservatism built in. Whereas, some of the later satellites like APPLE were additionally subjected to random vibration levels, acoustic environment simulations were not carried out in the experimental satellites.

The essential features of a realistic flight simulation are the decreasing conservatism in testing and closer tolerances allowed in specifications. The challenges involved in simulation of simultaneous application of static loads in different directions have been met by development of automatic static loading set up with load checks and correction devices, notch or abort provisions, and multiple jacks for supplying loads.

With the setting up of a facility to perform modal analyses of large spacecraft for extracting modal parameters like mass, stiffness and damping, it is possible to update the analytical model for realizing optimum designs.

Another major element of spacecraft structural testing in ISRO was related to building of a $1100 \mathrm{~m}^{3}$ acoustic chamber at the National Aeronautical Laboratory. IRS and SROSS have been tested successfully in this facility. Acoustic testing will form an important component of the test program for all future ISRO satellites.

3.1c Structural analysis: The role of structural analysis is to develop mathematical models of structural behaviour and obtain solutions to support design and testing activities. Design validation and improvements to achieve minimum weight designs, providing inputs for testing and correlation of analytical models with test data, are the important functions of analysis. 
The analysis tool is essentially centred around the finite element method which was developed over the last 30 years somewhat in parallel with the growth of computers. These two, in fact, contribute enormously towards fulfilling analysis needs. However, over the years, the increasing complexity of analysis can be seen from the over ten-fold increase in the sizes of idealisation of static and dynamic models from Aryabhata to INSAT II (see figure 3). Apart from the sheer increase in the size of problems, functionally there has been growth and diversification of activities. Static analysis and free vibration were considered sufficient in the earlier years of Aryabhata and Bhaskara due to lesser needs and paucity of resources. Presently, analysis encompasses in addition to the above, creation of low order dynamic models, subsystem modelling, analysis of accuracies in representing dynamic behaviour especially for large sizes, computer-aided design, optimization, correlation with test data and model improvements, creation of unified data bases, consideration of nonlinearities and so on.

The increasing complexity of satellites has been reflected in attempts at the development of extensive data-integrity checks, detailed subsystem modelling and development of computer-aided design packages for interactive design. Inherent difficulties in handling large-sized dynamic problems, often infeasible by direct methods, have necessitated work on dynamic substructuring which is also useful in providing inputs to testing of the units of a large structure, which cannot be tested as a whole. Emphasis on mass reduction needs optimization routines. Efforts on IRS and INSAT II reflect much of this higher level sophistication in analysis.

In a nutshell, the evolution of structural design, analysis, and testing methods have led to the realization of optimal structural hardware for satellites like IRS and INSAT II. Further, such improved and sophisticated approaches have also resulted in a reduced number of models to be built for design validation through testing in view of the higher degree of confidence in the design, analysis, and testing methods for the current satellites.

\subsection{Thermal control system}

The thermal control system of a spacecraft enables maintenance of the temperature of the different systems within specified limits while the spacecraft is in orbit. During its normal operations in space, a near-earth orbiting spacecraft receives heat input from the internal operation of the equipment, externally from the sun $\left(140 \mathrm{~mW} / \mathrm{cm}^{2}\right)$, in the form of reflected albedo radiation $\left(48 \mathrm{~mW} / \mathrm{cm}^{2}\right)$, and emission radiation $\left(23 \mathrm{~mW} / \mathrm{cm}^{2}\right)$ from earth. Further, the spacecraft radiates heat back into space, which is at a temperature of about $3 \mathrm{~K}$. The objective of the thermal control design is to realize acceptable equilibrium temperatures for the different systems taking into account various heat inputs and outputs.

Realization of an effective thermal control system involves three major elements. They are design of suitable control system, thermal analysis and thermal testing.

3.2a Thermal design and analysis: The type of thermal control system to be used for a particular spacecraft depends on the geometry of the spacecraft, mission phases, stabilization, power dissipation inside the spacecraft and the temperature ranges specified for various systems which are housed in the spacecraft. Table 1 gives the thermal design trends from the first Indian spacecraft Aryabhata to IRS-1 
Table 1. Thermal design trends from Aryabhata to IRS and INSAT

\begin{tabular}{|c|c|c|c|c|}
\hline $\begin{array}{l}\text { Aspect } \\
\text { considered }\end{array}$ & $\begin{array}{c}\text { Aryabhatal } \\
\text { Bhaskaral } \\
\text { Rohini missions }\end{array}$ & APPLE & IRS-1 & INSAT II TS \\
\hline $\begin{array}{l}\text { Temperature } \\
\text { control } \\
\text { requirement }\end{array}$ & $\begin{array}{l}0-40^{\circ} \mathrm{C} \text { for elec- } \\
\text { tronic packages, } \\
0-35^{\circ} \mathrm{C} \text { for } \mathrm{TV} \\
\text { camera and wider } \\
\text { ranges for sensors } \\
\text { and pneumatic } \\
\text { systems }\end{array}$ & $\begin{array}{l}5-25^{\circ} \mathrm{C} \text { for bat- } \\
\text { tery, } 5-55^{\circ} \mathrm{C} \text { for } \\
\text { reaction control } \\
\text { system and } 0-40^{\circ} \mathrm{C} \\
\text { for electronic } \\
\text { packages }\end{array}$ & $\begin{array}{l}0-10^{\circ} \mathrm{C} \text { for bat- } \\
\text { tery, } 10-20^{\circ} \mathrm{C} \text { for } \\
\text { payload, } 5-55^{\circ} \mathrm{C} \\
\text { for } \mathrm{RCS} \text { and } \\
0-44^{\circ} \mathrm{C} \text { for elec- } \\
\text { tronic packages }\end{array}$ & $\begin{array}{l}5-25^{\circ} \mathrm{C} \text { for battery, } \\
5-55^{\circ} \mathrm{C} \text { for } \mathrm{RCS} \text {, } \\
\text { VHRR detector to } \\
\text { be maintained at } \\
105 \pm 0.1 \mathrm{~K} \text { in } \\
\text { presence of solar } \\
\text { sail and boom }\end{array}$ \\
\hline $\begin{array}{l}\text { Size of } \\
\text { thermal } \\
\text { mathematical } \\
\text { model }\end{array}$ & Less than 20 nodes & 154 nodes & $\begin{array}{l}450 \text { nodes. De- } \\
\text { tailed model for } \\
\text { critical systems like } \\
\text { payload, battery, } \\
\text { RCS etc. }\end{array}$ & $\begin{array}{l}500-1000 \text { nodes. } \\
\text { Detailed model } \\
\text { for VHRR, com- } \\
\text { munication pay- } \\
\text { load, RCS, solar } \\
\text { sail and boom etc. }\end{array}$ \\
\hline $\begin{array}{l}\text { Technology } \\
\text { involved }\end{array}$ & $\begin{array}{l}\text { Passive system, } \\
\text { paints using se- } \\
\text { lected optical pro- } \\
\text { perties and geo- } \\
\text { metry, radiation } \\
\text { shields and FRP } \\
\text { insulation }\end{array}$ & $\begin{array}{l}\text { System consisting } \\
\text { of MLI blankets, } \\
\text { optical tapes, sur- } \\
\text { face property con- } \\
\text { trol, ground-com- } \\
\text { manded heaters }\end{array}$ & $\begin{array}{l}\text { System consisting } \\
\text { of MLI blankets, } \\
\text { rigid OSR, propor- } \\
\text { tional controllers } \\
\text { and ground-com- } \\
\text { manded heaters. }\end{array}$ & $\begin{array}{l}\text { System consisting } \\
\text { of MLI blankets, } \\
\text { rigid optical solar } \\
\text { reflector, propor- } \\
\text { tional and ground } \\
\text { commanded heaters, } \\
\text { passive cooler for } \\
\text { VHRR, solar sail } \\
\text { and boom }\end{array}$ \\
\hline $\begin{array}{l}\text { Test } \\
\text { philosophy }\end{array}$ & $\begin{array}{l}\text { Scale model tests } \\
\text { with bonded hea- } \\
\text { ters or no tests }\end{array}$ & $\begin{array}{l}\text { Full-scale solar } \\
\text { simulation test in } \\
7 \mathrm{~m} \text { chamber, and } \\
\text { one acceptance } \\
\text { test in } 4 \mathrm{~m} \text { cham- } \\
\text { ber with bonded } \\
\text { heaters }\end{array}$ & $\begin{array}{l}\text { Full-scale test on } \\
\text { structural/thermal } \\
\text { model with bon- } \\
\text { ded heaters. Solar } \\
\text { simulation test on } \\
\text { engineering/ther- } \\
\text { mal model and IR } \\
\text { acceptance test on } \\
\text { flight model }\end{array}$ & $\begin{array}{l}\text { Full-scale solar } \\
\text { simulation test on } \\
\text { engineering/ther- } \\
\text { mal model in a } \\
9 \mathrm{~m} \mathrm{dia} \text { thermo- } \\
\text { vacuum chamber } \\
\text { and one accep- } \\
\text { tance test on flight } \\
\text { model }\end{array}$ \\
\hline
\end{tabular}

and INSAT II TS. The thermal control system in Aryabhata used passive techniques consisting of selected optical surfaces, radiation shields and insulation to control the subsystem electronics package temperature between 0 and $40^{\circ} \mathrm{C}$ during its one year design mission life. APPLE spacecraft needed multilayer insulation (MLI) blankets to insulate the spacecraft from sun irradiation and to minimize the power radiated into space during eclipse periods. In addition to selected optical surfaces, ground-commanded heaters were necessary to control the temperature of its reaction control system elements between 5 and $55^{\circ} \mathrm{C}$. The current generation of spacecraft like IRS-1 and INSAT II call for the use of improved active and passive thermal control systems in view of the higher power loads, closer temperature ranges, cooling of detectors in payloads like those used in remote sensing, reduced thermal gradients etc. IRS-1 poses a much greater challenge than APPLE because of very narrow temperature ranges specified for power and chemical batteries. In addition to $0-10^{\circ} \mathrm{C}$ temperature range in case of the payload, the gradient within a camera has to be less than $2^{\circ} \mathrm{C}$. The design approach is to minimize external thermal loads on the camera by providing two sets of shields and maintaining the 
temperature using the proportional control heaters. A separate radiator has been provided for the battery so that the temperature excursion of the rest of the spacecraft does not affect the temperature control of the battery. Further, the temperature is controlled within the range by means of proportional controllers. In case of INSAT II TS in order to maintain the temperature of the $\mathrm{Hg}$-Cd-Te infrared detector used in the Very High Resolution Radiometer (VHRR) payload around $105 \pm 0 \cdot 1 \mathrm{~K}$. a passive radiation cooler is employed.

As the specified temperature range becomes narrower, it becomes essential to prepare detailed thermal mathematical models for the integrated spacecraft and for the critical systems housed in the spacecraft. The size of the thermal mathematical model has increased from 17 isothermal nodes in Aryabhata to 450 nodes in IRS-1. The size is higher for spacecraft like INSAT II TS. Another evolving feature is the detailed modelling at subsystem levels. A detailed mathematical model was prepared for Reaction Control System (RCS) of APPLE. In case of IRS-1, detailed mathematical models are prepared for payload, battery, RCS, solar panel and yoke. In INSAT II TS, separate analysis will be made for solar sail and boom, communication payload, VHRR payload, reflectors, solar panels and propulsion systems. The thermal control systems design and analysis work becomes more and more complex as the power dissipation of the payload increases and the specified temperature range narrows down as is expected in future satellites of the IRS and INSAT series.

3.2b Thermal testing: The thermal design as well as the performance of the thermal control system are verified on ground by testing the spacecraft in a thermovacuum chamber. The effect of the sun-load, can be simulated by means of a xenon-solar simulator or IR heaters. In case of IR heaters, only the absorbed load can be simu'ated. The planning and conduct of test activity is quite complex due to several reasons. The accuracy of simulation depends on various factors like size of satellite in relation to chamber size, the nature of various interfaces/fixtures used in the chamber and also the extent to which shapes, surface and orbital modes are simulated. However, error in heat exchange, in simulation of cold black space by a liquid nitrogen shroud, will be less than $1 \%$. Further, in simulating solar beams by a xenon lamp, non-uniformities along the cross-section area and collimation errors cannot be avoided. One major issue involved is the very high cost of solar simulation. Hence, trade-off considerations are involved in the use of alternate methods like IR simulation, which have limitations in accuracy especially when there are large projections on the spacecraft surface which form shadows or exchange heat locally.

In the case of Aryabhata and Bhaskara, simple scaled-down models, with heaters simulating both the external and internal heat inputs were fabricated and tested in the thermovacuum chamber. The temperature accuracy in such tests was of the order of $\pm 5^{\circ} \mathrm{C}$. In case of APPLE spacecraft, solar simulation tests were conducted in an external facility. A test was also carried out using IR heaters in a 4-meter diameter chamber in India, which does not have a solar simulator. A similar approach has been adopted for IRS. A large simulation chamber of about $9 \mathrm{~m}$ dia, with a $4 \mathrm{~m}$ solar beam is being planned in ISRO for testing future spacecraft like INSAT II and follow-on IRS series.

Figure 4 illustrates the trends in the usage of thermal contrel elements, the testing concepts and the analysis modelling for Indian satellites. 


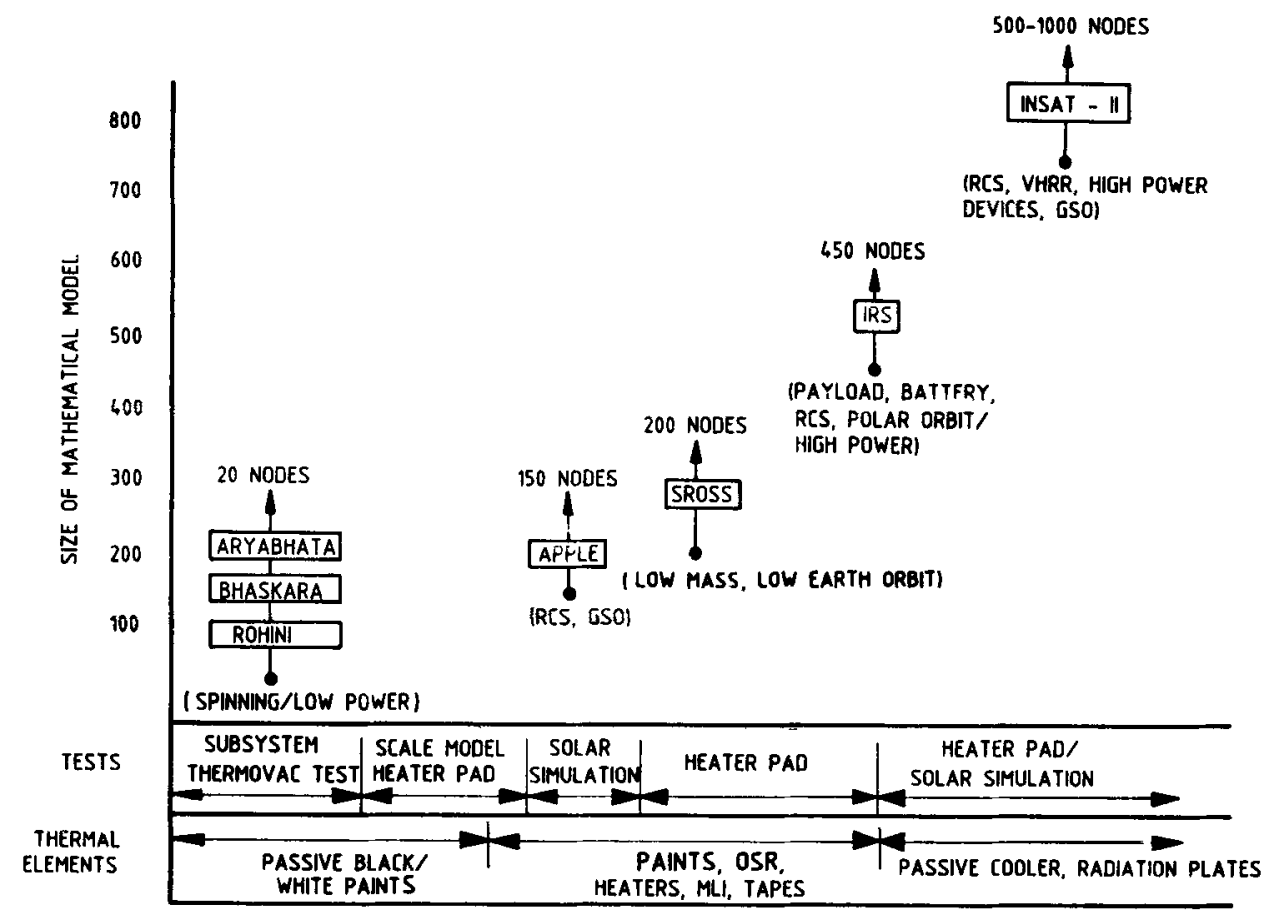

Figure 4. Trends in usage of thermal control elements, testing concepts and analysis modelling for Indian satellites. Details in paranthesis indicate the features/characteristics of the satellite systems or its orbit that have a bearing on thermal analysis and modelling.

The trend in thermal design and analysis is such as to meet the more stringent performance requirements (like smaller temperature excursions on specific subsystems, lower gradients etc) and evolving testing methodologies that result in closer simulation of actual orbital conditions and hence, more accurate evaluation of the thermal performance of spacecraft.

\subsection{Spacecraft mechanisms}

Spacecraft mechanisms are used to deploy systems like solar panels and antennae, which are stowed during the launch phase within the rocket heat shield and deployed subsequently in orbit. Other type of mechanisms used in spacecraft include booms which deploy instruments and unfurling mechanisms typically used for large antennae. Aryabhata, Bhaskara and Rohini satellites did not call for deployable elements as they had body-mounted solar panels and there were no other specific requirements. APPLE for the first time used a deployment system to deploy its two solar panels located symmetrically on either side.

Recently, ISRO has undertaken the design and development of deployment mechanisms for large solar panels used in its IRS, SROSS and INSAT II spacecraft. The mechanisms used in spacecraft like INSAT II carry out the total deployment of panels in a sequential manner. The INSAT II spacecraft also employs another 
mechanism called coilable lattice boom, $14.95 \mathrm{~m}$ long when deployed, to correct the radiation imbalance torque generated by one-sided solar panels.

The notable challenges posed during the development of mechanisms include (i) simulation of thermal gradients at various parts of the mechanisms overcoming the difficulties involved in simulating exact boundary conditions at different places, and (ii) handling of the flexible mechanisms and conduct of zero- $g$ simulated tests on them. On the analytical side also, these systems present complexities since the analytical models for zero- $g$ conditions cannot be directly validated through zero- $g$ tests, especially for mechanisms employing flexible structures. Hence, these are to be developed for $1-g$ conditions, validated through a test and then modified for zero- $g$ conditions. Since most of these mechanisms are mission-critical items, they need to undergo elaborate testing to establish a high level of reliability within the constraints of simulating all space conditions.

\subsection{Power system}

The satellite power system has the function of generating the necessary power under different orbital and operating conditions of spacecraft as well as power conversion involving regulation and control of output to satisfy the requirements of satellite subsystems and payloads.

Power needs of Indian satellites have grown from a few Watts to the kiloWatt range. The technologies of power generation, storage and management, in response to these needs, have undergone significant improvements. While the Rohini series of satellites needed only 5 Watts, the INSAT II TS will call for the generation of a kiloWatt of power. Besides the magnitude of the power needed, mission-life requirements have grown from a few months to about 7 years. Varied requirements of power and mission, combined with high reliability, are the challenges to be met by the power system designer.

A satellite power system mainly comprises three major elements: power generation, storage and management. In the area of power generation, involving the use of panels with silicon solar cells, the thrust is to achieve high power per unit area, high power per unit weight, and the ability to withstand thermal, mechanical and radiation environments. Energy storage using chemical batteries to supply eclipse and peak requirements, need to have high energy storage density and long life. Power management using circuitry should achieve high system efficiency along with fault-tolerant interfaces to provide appropriate control over the generator and the storage elements.

3.4a Power generation: The basic device used for power generation in Indian spacecraft is the silicon $n / p$ solar cells. In this area, efforts are directed towards improving the cell efficiency by way of development of back-surface reflector or back-surface field with reflector type cells, reliability and resistance to charged particle radiation. Technology of coverglass and cell interconnects (CIC) using indigenous solar cells have been developed in the country. Construction of a solar array involving thousands of cells is a complex process utilizing several advanced technologies. The design of solar panels has employed a rigid honeycomb structure with aluminium faceskin. Significant developments in interconnector design, solar cell welding and bonding, have been incorporated in the solar panel fabrication to 
meet the stringent design goals of 24,000 thermal cycles $\left(-100\right.$ to $\left.+100^{\circ} \mathrm{C}\right)$ for spacecraft like IRS with the demand of a 3-year life. Figure 5 illustrates the evolutionary improvements in solar panel technology.

3.4b Energy storage: Presently, energy storage is achieved by secondary Ni-Cd batteries. Limited battery life constrains its design and application. Battery temperature control is very crucial for meeting the life-time requirements. This involves detailed study of the thermal behaviour of the battery. under different charge/discharge conditions. It also calls for sophisticated battery charge control techniques. Another important area in battery technology is its structural design which has to be of mimimum weight to meet the mechanical requirements and also to satisfy the thermal control requirements.

The design and technology for fabrication of batteries using $\mathrm{Ni}-\mathrm{Cd}$ cells has been qualified for SROSS satellites. Further, simulation efforts, with much more stringent design goals for IRS and INSAT II spacecraft, are presently under way. Efforts to develop $\mathrm{Ni}-\mathrm{Cd}$ cells indigenously have also been taken up in collaboration with Indian Industry.

3.4c Power management: Power management has a number of elements that include regulating the generated power, controlling the charge and discharge,
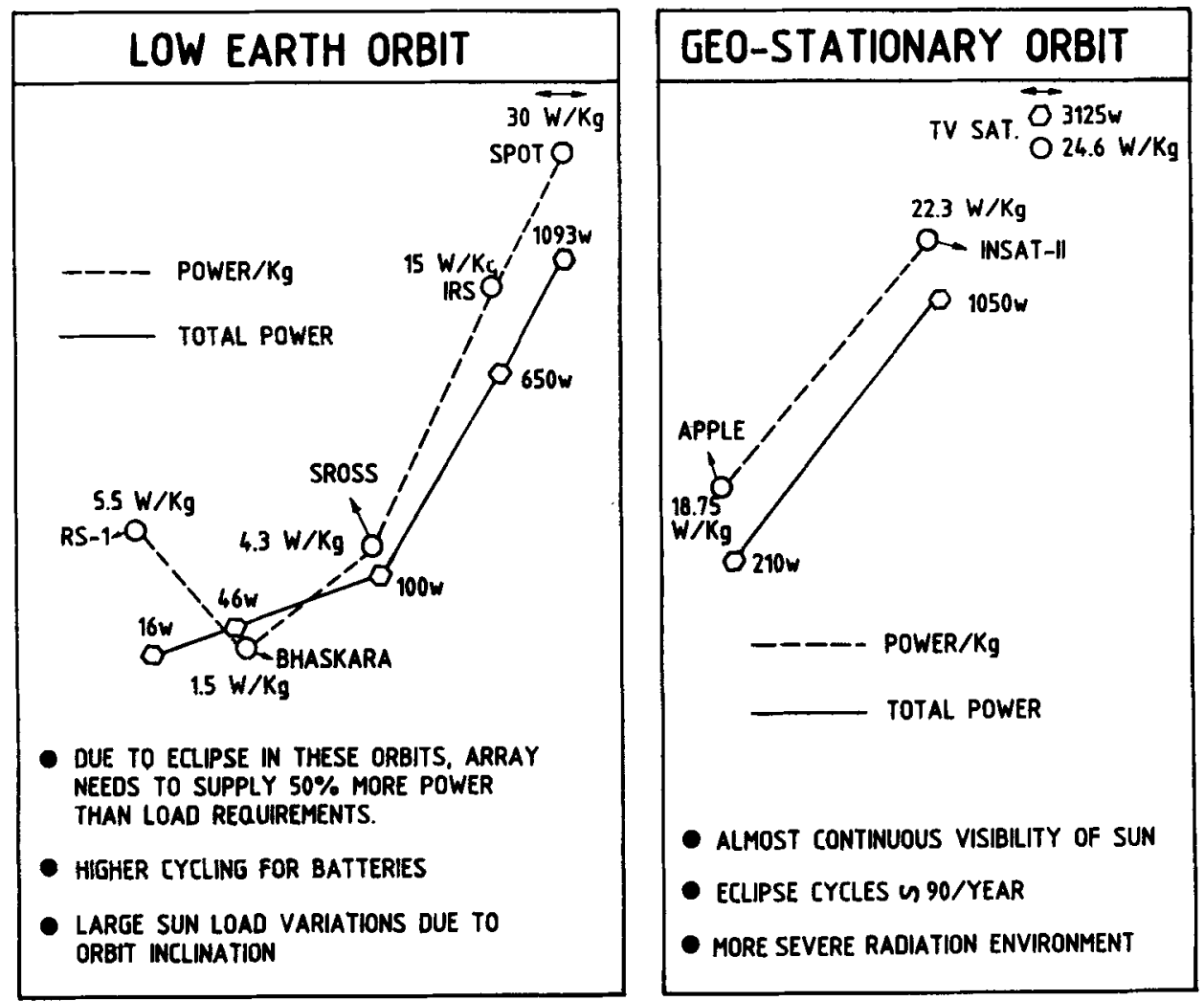

Figure 5. Evolutionary improvement in solar power systems of Indian satellites $(\longleftrightarrow$ indicates state of art). 
distributing power, meeting user requirement, providing fault tolerance and isolation against user malfunction, and monitoring of the generator and storage elements.

The modest power needs of earlier satellites like Rohini and Bhaskara, were met by a centralized system. Higher power requirements of the present generation spacecraft necessitate the development of distributed power systems employing novel techniques to achieve high efficiency, lower weight and volume, modular design and lower electro-magnetic interference. In order to perform the in-orbit battery management optimally, sophisticated battery control techniques have been developed including control of its thermal environment. For achieving battery efficiency and power density in power control, development of power inversion and AC distribution techniques at $50 \mathrm{~Hz}, 400 \mathrm{~Hz}$ and $20 \mathrm{kHz}$ using computer-aided design techniques, is under way. Better design techniques incorporating series resonant power conversion and very low EMI, isolated CuK converter are being planned. Better packaging technologies using hybrid microcircuits have been undertaken. Modelling and analysis studies of nonlinear converters to achieve better frequency response, lower $\mathrm{AC}$ output impedance and higher audio susceptibility are also being taken up. Table 2 gives a summary of the trends in power systems growth for ISRO satellite missions.

On the whole, in the case of the power system, the drive is to realize highly reliable, efficient and long-life systems while keeping the increasing demands of power for satellites like INSAT II in view.

\subsection{Attitude control system}

Attitude control of a spacecraft (Scull 1966) is the orientation of its fixed axes with respect to a desired reference frame, thereby providing the necessary alignment for the operation of payloads, sensors, antenna and evin solar panels. The relevant information about the attitude is generated by a system of sensors that sense the directions of certain well-known 'landmarks' in space such as the sun, the earth's magnetic field, the infrared horizon of the earth or some bright stars. There are at least four major elements to the design of a control system for a spacecraft. These include mission analysis, dynamic and reliability analysis, hardware implementation, and finally, testing and design evaluation.

Table 2. Power system growth for ISRO satellite missions

\begin{tabular}{|c|c|c|c|c|c|c|c|}
\hline \multirow[b]{2}{*}{ Spacecraft } & \multirow{2}{*}{$\begin{array}{l}\text { Launch } \\
\text { year(s) }\end{array}$} & \multirow[b]{2}{*}{ Orbit* } & \multicolumn{2}{|c|}{ Power level (W) } & \multirow{2}{*}{$\begin{array}{c}\text { Solar array } \\
\text { size }\left(\mathrm{m}^{2}\right)\end{array}$} & \multirow{2}{*}{$\begin{array}{c}\text { Battery size } \\
(\text { Amp hr)(cells })^{\dagger}\end{array}$} & \multirow{2}{*}{$\begin{array}{c}\text { Design life } \\
\text { (years) }\end{array}$} \\
\hline & & & Raw & Regulated & & & \\
\hline Rohini series & $1980,81.83$ & LEO & 16 & 5 & 0.97 & $1 \cdot 6(12)$ & 0.25 \\
\hline Aryabhala & 1975 & LEO & 46 & 10 & 3.7 & $10(20)$ & $0 \cdot 5$ \\
\hline Bhaskara & 1979. 1981 & LEO & 47 & 15 & 3.7 & $10(20)$ & 1 \\
\hline APPLE & 1981 & GEO & 210 & 100 & $2 \cdot 86$ & $12(16)$ & 2 \\
\hline SROSS-1 & 1987 & LEO & 100 & 30 & $7 \cdot 2$ & $12(12)$ & $0 \cdot 5-1$ \\
\hline IRS-1 & 1988 & LEO & 650 & 250 & $8 \cdot 5$ & $2 \times 40(16)$ & 3 \\
\hline INSAT II TS & 1989 & GEO & 1050 & 750 & 14 & $2 \times 17(28$ each $)$ & 7 \\
\hline
\end{tabular}

\footnotetext{
* LEO-low earth orbit; GEO-geostationary earth orbit; ${ }^{\dagger}$ Values in parentheses are the number of cells in the battery.
} 
In the mission-analysis phase, the overall mission profile, vis-a-vis, the attitude control requirements are examined. The availability of ground-support facilities and the interfaces between the on-board and the ground systems are additional considerations in mission analysis. Further, the activities include identification of failure modes, contingency procedures and the development of mission operations software compatible with the available computational facility.

Dynamics analysis is carried out for various control modes, ensuring stability for all possible mass distributions and flexibilities as well as disturbances such as gravity gradient, magnetic, solar radiation, aerodynamic, and those arising from the operation of the on-board hardware. Stability analysis is done for all possible modes including transition modes from one phase to another.

The implementation of an attitude control system has several approaches that can be broadly classified as passive, semi-passive, active and hybrid.

3.5a Earlier systems: Two of the common methods of attitude control are spin stabilization and three-axis control. Spin stabilization essentially involves spinning the satellite normally about the axis of the maximum moment of inertia and subsequent maintenance of the desired spin rate and spin-axis orientation. Three-axis control, on the other hand, involves a feedback loop for each of the axes wherein the attitude errors are sensed by sensors and the control electronics processes this information to implement the desired control laws and drives the torquing devices. Earlier Indian satellites like Aryabhata, Bhaskara I and II, RS-D1 and D2, with body-mounted solar panels, were spin stabilized. However, as the payloads become more sophisticated, the demands on the specifications of attitude errors, body rates and jitter become more stringent. In addition, with the increase in the size and complexity of the spacecraft, the associated power requirements also increase. The natural solution to these requirements is found in the use of deployed solar panels and the 3-axis mode of attitude control. APPLE was India's first experimental geostationary communication satellite wherein our 3-axis control capability was first established.

3.5b Current systems: In respect of the current programmes, the 3-axis stabilization system for IRS is based on a 'zero-momentum' four reaction wheels configuration (with redundancy for any one wheel-failure) for the normal mode and RCS thrusters for acquisition and orbit control modes. Unlike the case of APPLE, IRS has a stringent specification on the platform stability of $3 \times 10^{-4}$ deg $\mathrm{s}^{-1}$ during the payload operation. This was perhaps the single most challenging feature in the IRS control system design and was eventually achieved with the implementation of a coarse compensation for the momentum coupling of the roll and yaw wheels and an extended Kalman filter which estimates the uncompensated coupling torques in addition to the attitude errors and rates. Another salient feature is the automatic detection and reconfiguration of the reaction wheel system in the event of a failure in one of the wheels, without any interruption in the control system performance.

The overall control system designed has to be fairly robust in the presence of parametric variations, noise and single-point failures, and yet has to be simple and reliable. Thus, the dynamics modelling and control system design has to be carried out with extreme care and has to be backed up by extensive eomputer and hardware-in-the-loop simulations, incorporating all the characteristics of the 
hardware elements, nonlinearities, noise and scale factors. These simulations should embrace not only the normal mode performance but should comprehensively cover all the conceivable failure modes as well.

While the computer simulations form the heart of the overall control system design, an important concept in the design validation, particularly for high performance spacecraft like IRS entails the use of a 3-axis servotable. Here, the servotable reproduces the computer simulated motion with high accuracy. The various sensors are mounted on the servotable with earth and sun simulators and the other hardware such as the control electronics and actuators are kept in environmental chambers. The computer interfaces with these components in real time and collects all the relevant data which, in turn, are fed to the spacecraft dynamics model in the computer.

In the case of INSAT II, the control system design is a complex and innovative task. The use of a microprocessor-based system is inevitable, as it would facilitate the implementation of sophisticated control techniques as well as the safety features of automatic reconfiguration of wheels, RCS, sensors and automatic redundancy management at the subsystem level. An important constraint that has to be satisfied at all times, including during any of the complex control manoeuvres and also during any contingency operations, is that the sun should not be in the field of view of the Very High Resolution Radiometer (VHRR) cooler.

Two other major areas that have to be addressed additionally, are the effects of liquid sloshing and interaction of control with flexible structure. INSAT II during launch carries about $800 \mathrm{~kg}$ of liquid propellant. A detailed analysis has to be carried out to ensure that the presence of such a large amount of fluid does not introduce any adverse dynamic condition and the 'slosh' does not cause instability in any of the modes. Regarding the second aspect, with a solar sail on the north face for balancing the disturbance torques due to the action of the solar radiation pressure on the large array of solar panels on the south face, a detailed study on the control-flexible appendage interaction becomes indispensable as already stated earlier. This would essentially involve the modelling of the flexible body dynamics in terms of the frequencies and mode shapes for the flexibility modes and using this information together with the control torques to compute the reflected torques developed on the spacecraft body. The performance of the control system can then be evaluated through elaborate computer simulations.

Coming to the control electronics, the Attitude Control Electronics (ACE) does the on-board processing needed for spacecraft control and generates the control signals for driving the actuators. As the control system requirements become stringent, the ACE is required to carry out many functions involving a lot of high speed computations. Further, the system has to be versatile and flexible. Although some of the earlier spacecraft such as Bhaskara I and II and APPLE had entirely discrete IC-based hard-wired systems, partially microprocessor-based control electronics have been developed for RS-D1 and D2, SROSS and IRS satellites. Microprocessor-based systems offer a lot of flexibility and multi-mission adaptability. "Remote programmability" feature is incorporated in the SROSS ACE to cope with unanticipated problems/failure modes. Microcomputer-based test systems have also been developed. To meet the large computational requirements of INSAT II and future satellites, bit-slice/multiprocessor-based systems incorporating fault tolerance and auto-reconfiguration features are under development. 


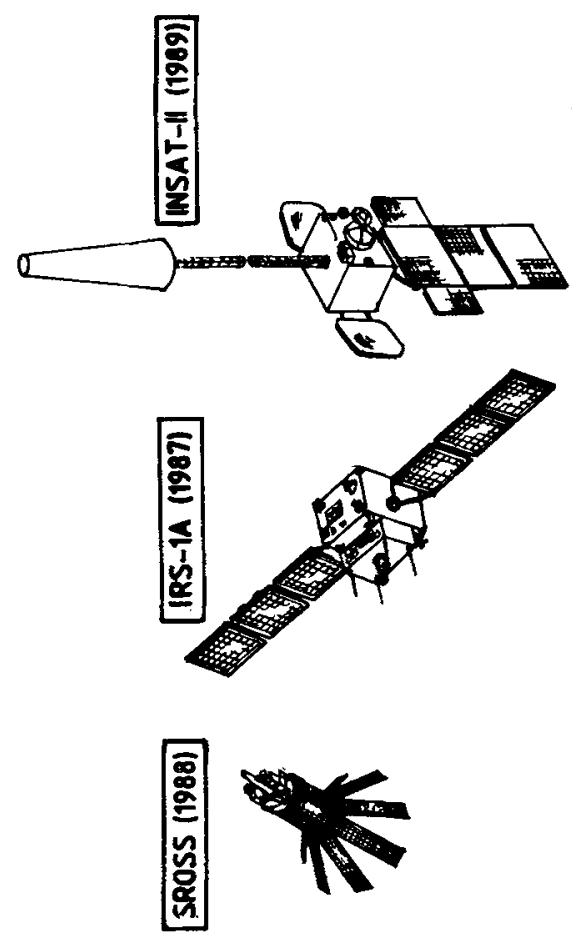

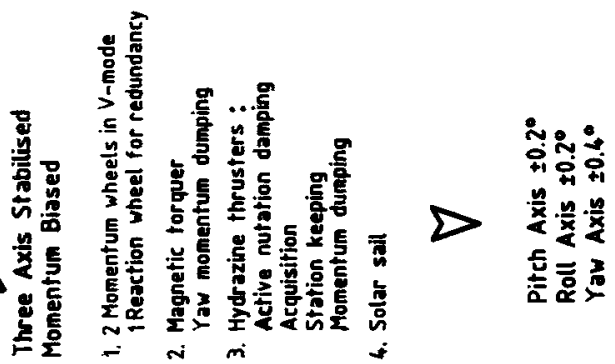
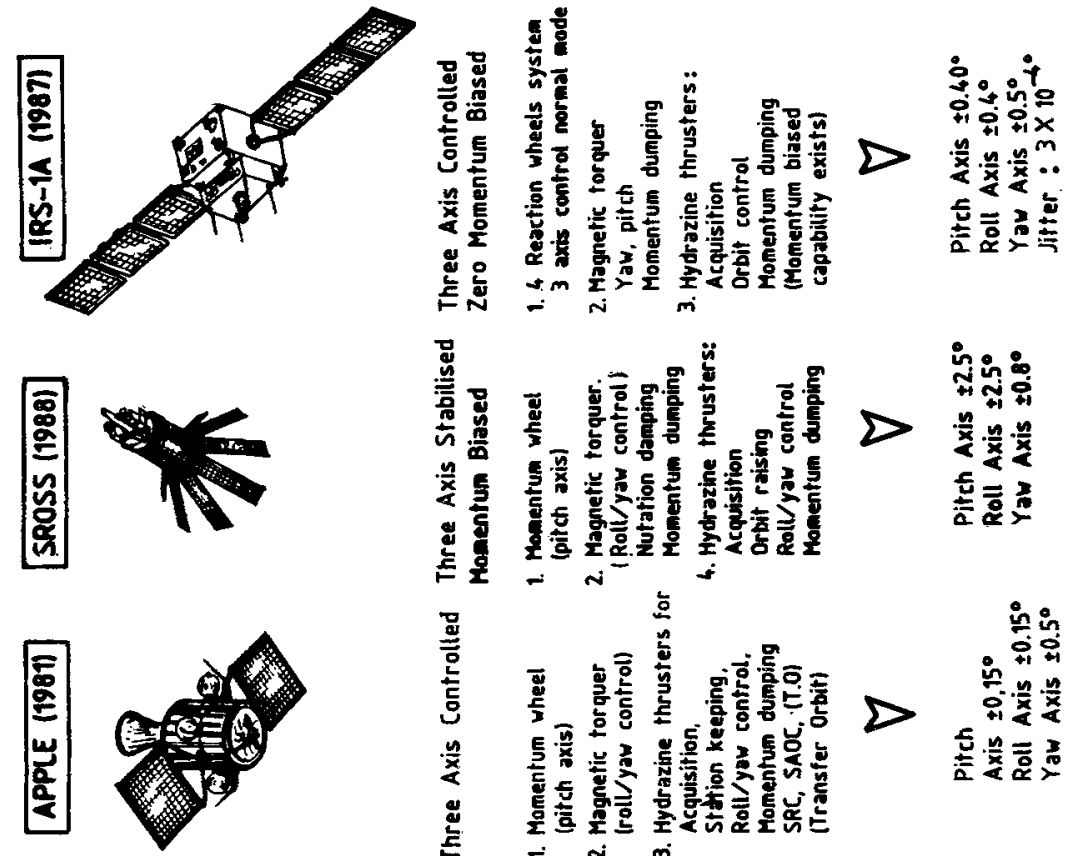

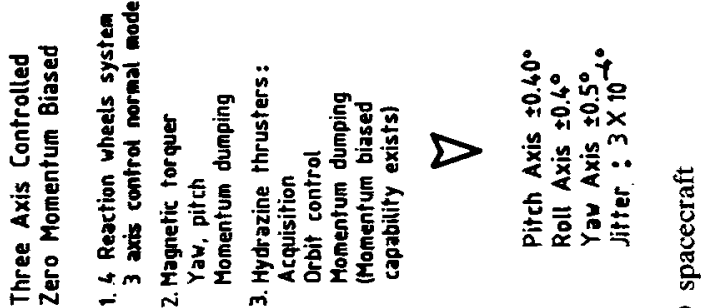

寅

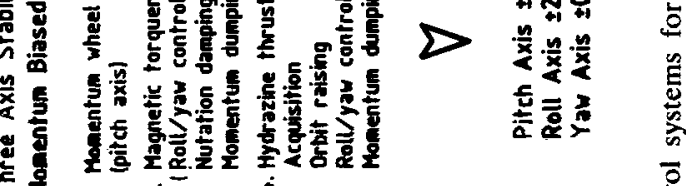
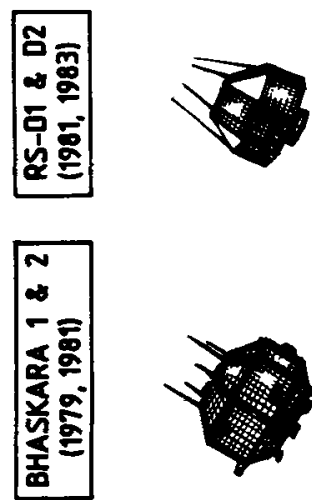

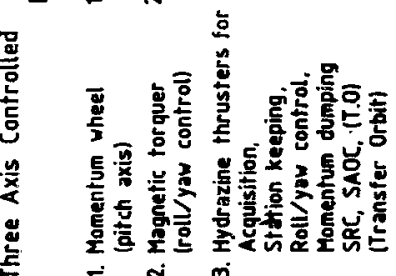

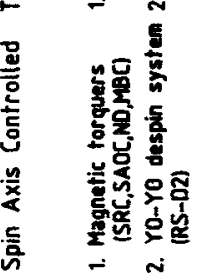

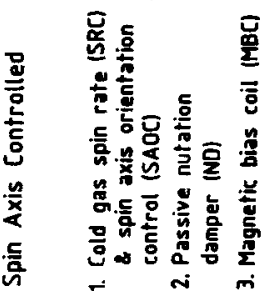
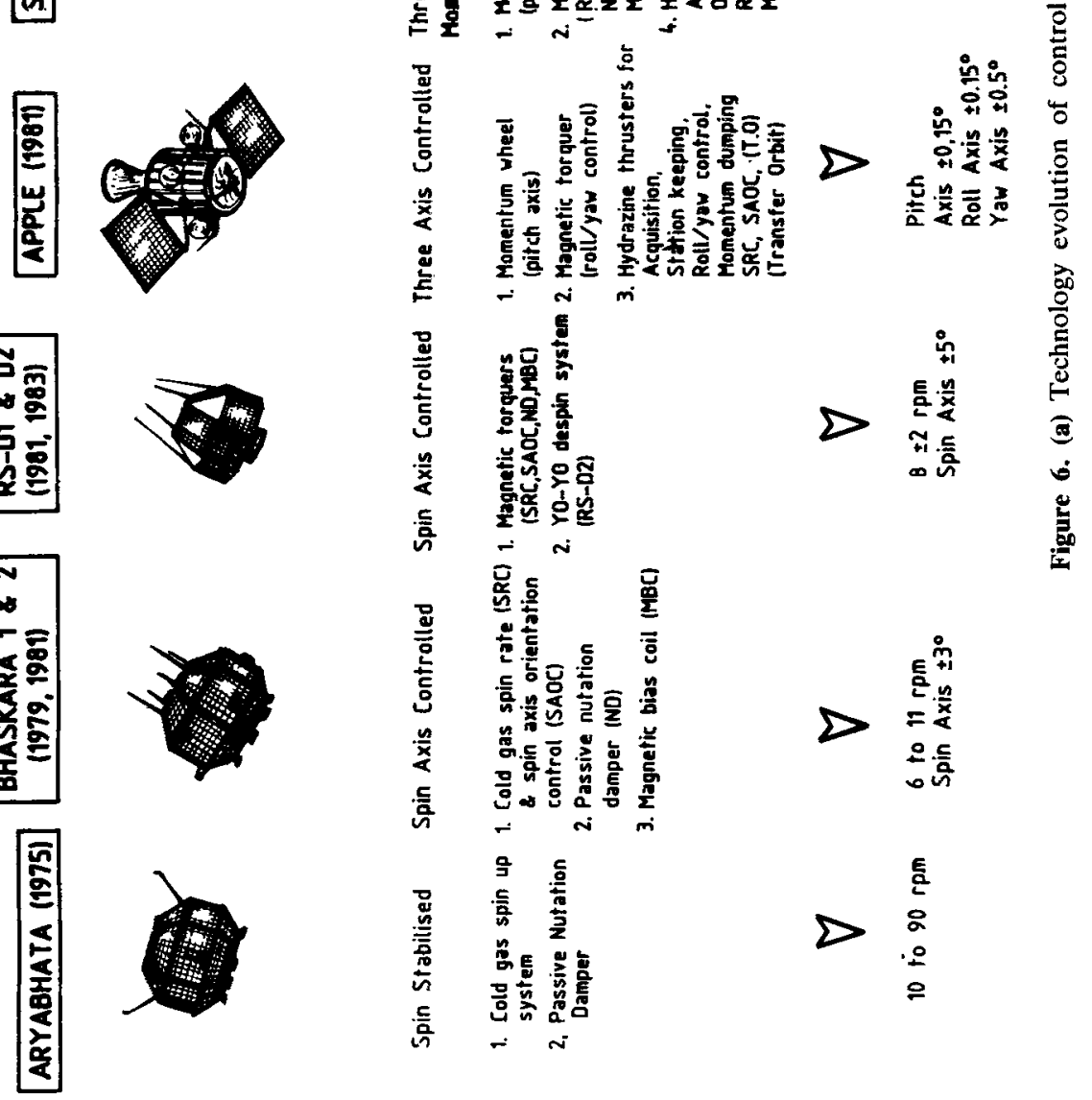

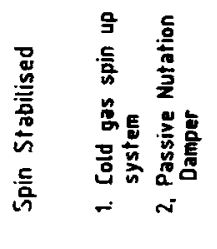
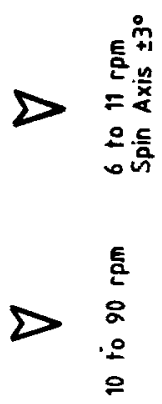


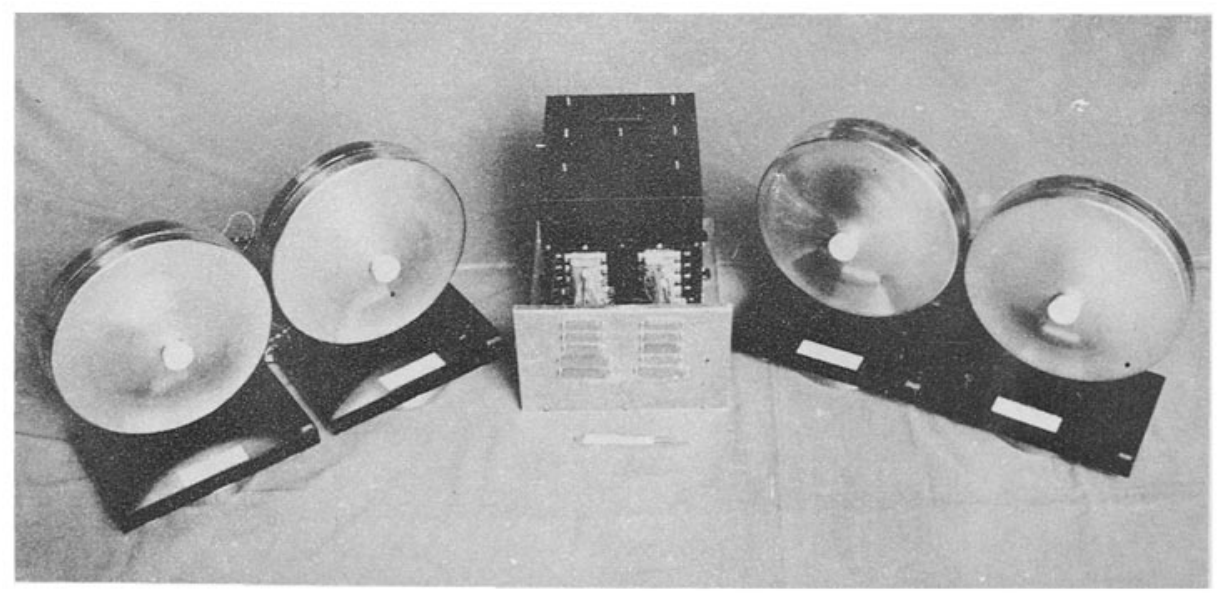

Figure 6. (b) Photograph of reaction wheels used in IRS.

Finally, mention should be made of the ISRO developments on some of the control system actuators like reaction wheels (RW), momentum wheels (MW), magnetic torquers, nutation dampers and reaction control systems (RCS). Magnetic torquers and nutation dampers were used in earlier satellites like Bhaskara and Rohini. APPLE additionally used a $20 \mathrm{Nm}$ momentum wheel. IRS and INSAT II will employ reaction wheels. The technology of wheels involve those related to bearing, lubrication, high reliability motors etc. Studies on problems of cage instability, involving bearing assembly in a cage, form an important aspect of development as also those related to long life dictated by design and implementation strategies for bearing and lubrication. The reaction control system in separately dealt with elsewhere in this paper.

Figure $6 \mathrm{a}$ shows the technology evolution of the control systems for ISRO spacecraft. As is evident, the drive is towards a higher degree of pointing accuracies, low jitter and drift rates and long life systems.

\subsection{Attitude sensors}

Attitude sensors (Singer 1964) are used for deriving information on the orientation of the satellite axes in space for control purposes and also for interpreting the data from the scientific and application experiments on board. Attitude sensors can be electro-optical, magnetic, electromagnetic or inertial.

Figure $7 \mathrm{a}$ shows the progressive sophistication in the attitude measurement of ISRO spacecraft involving the use of more accurate and precise attitude sensors.

3.6a IR horizon sensors: The technology of the horizon crossing earth sensor, compatible with the state-of-art, is well-established in ISRO and such sensors were flown in Bhaskara, Rohini and APPLE missions. Another sensor, called a Conical Horizon Sensor, is derived from the horizon crossing sensor by incorporating a scanning mechanism so that in a non-spinning satellite such as a three-axis stabilized satellite, the sensor can sense the horizon crossing. The scanning mechanism is provided by a germanium wedge which is rotated by means of a 

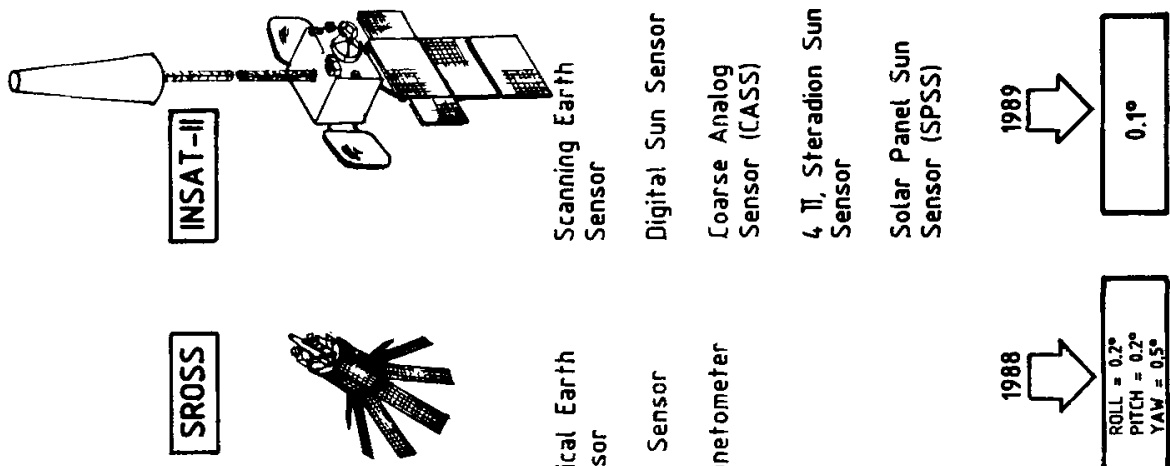

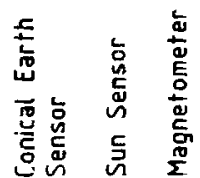
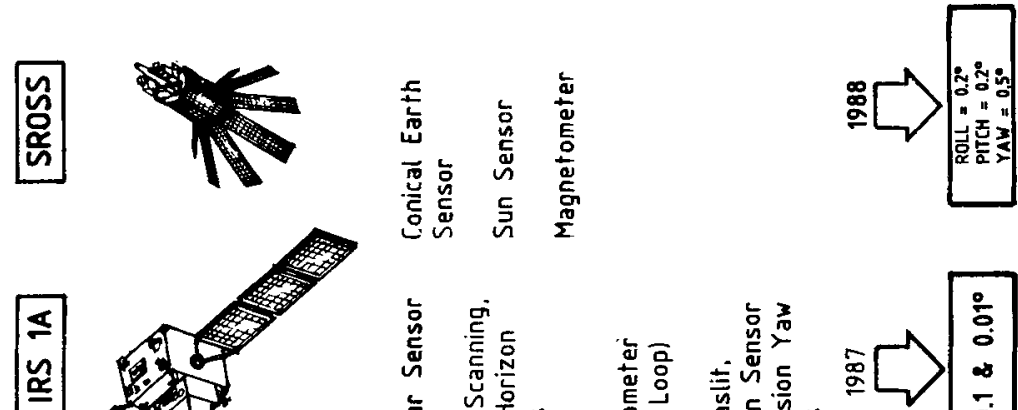

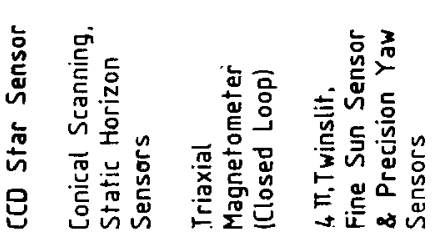

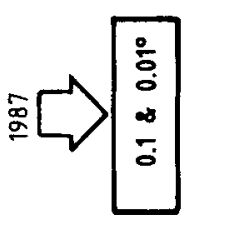

岩

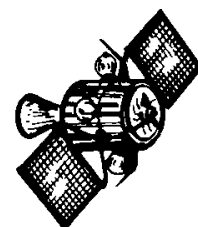

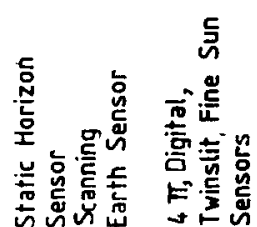

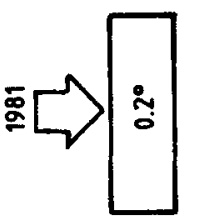

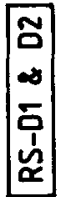

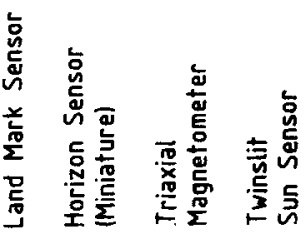

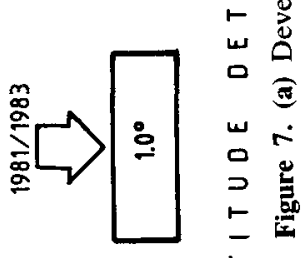

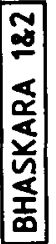

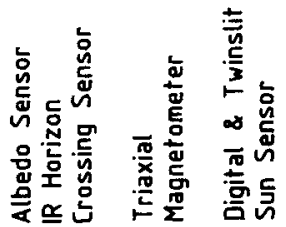

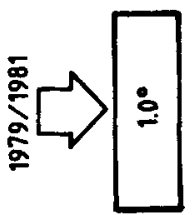

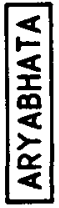

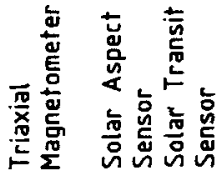

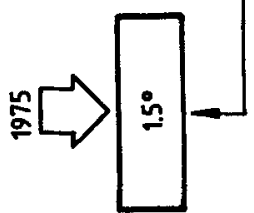




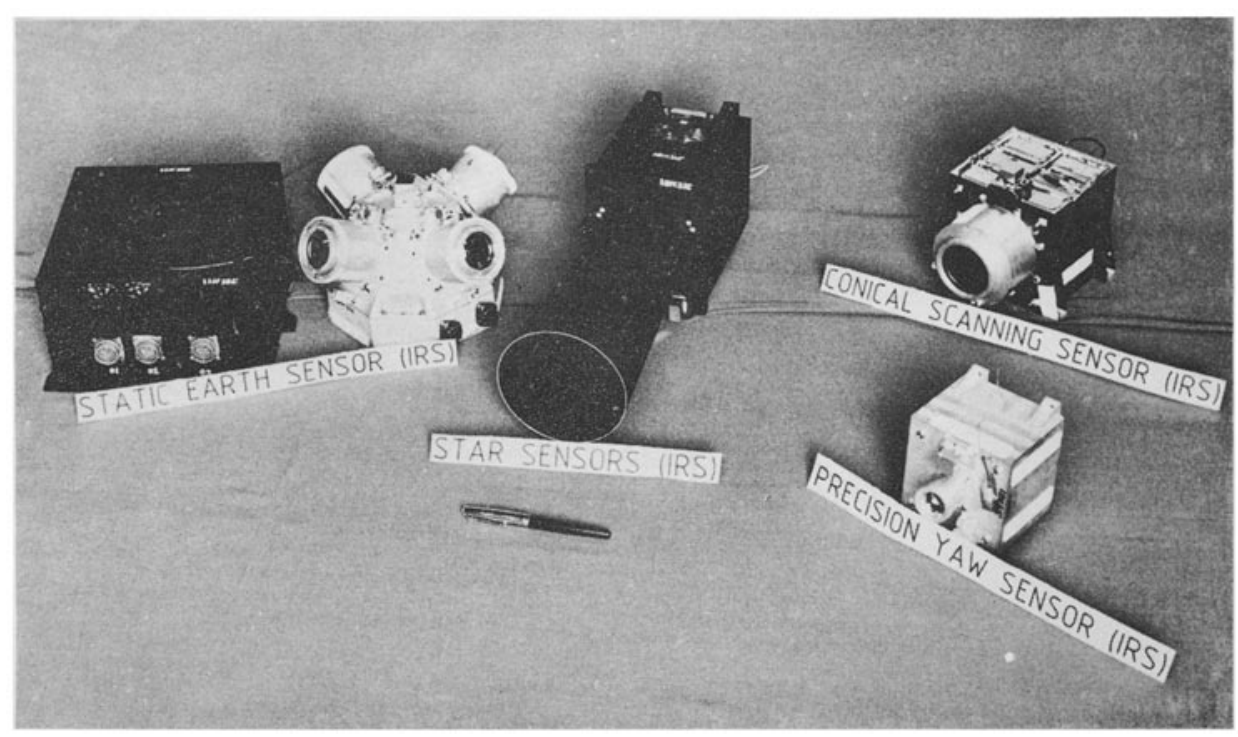

Figure 7. (b) Photograph of some of the ISRO-developed attitude sensors.

brushless d.c. motor. Sealed angular-contact duplex bearings are used in the system to ensure smooth uniform rotation with minimum oil vapour contamination on the optical elements. An angle encoder is incorporated to measure the earth pulse width to an accuracy of $0 \cdot 01^{\circ}$. The sensor is hermetically sealed to avoid evaporation of bearing oil and special feedthroughs are used to carry the IR detector signal to the processing electronics. Such a sensor has been developed for IRS.

Problems of mechanical scan motion and its associated reliability concerns can be avoided by using an alternate type of sensor called the static horizon sensor which uses four infrared telescopes viewing four symmetrical points at the periphery of the earth. By radiometrical balancing, a null is established and deviations in this represent roll and pitch errors. Thermopile detectors of special geometry are used as the sensing devices. Since the energy of the earth signals is far less than that radiated from the telescopes to space an accurate thermal analysis is required to detect the earth signal. Precise thermal control is maintained on the sensor telescope and a division technique is used to cancel the effect of variation of radiation in the 14 to 16 micron band due to the seasons. Besides this, extremely low drift d.c. amplifiers and low noise processing electronics are used which give a very low noise output. The only disadvantage of such a sensor is its inability to cover a wide angular range and its susceptibility to extreme thermal transients. One such sensor was flown in APPLE and another has now been developed for IRS.

While for a low earth mission, a rotating wedge could be used to scan the earth as in a conical sensor, for a geostationary mission, it is not worthwhile to scan $360^{\circ}$ since the earth subtends an angle of only $17^{\circ}$. Instead, it is preferable to scan more often using a scanning mirror and average the noise by collecting more samples. Such an approach is used in a scanning earth sensor which uses a metal scanning mirror in front of a horizon sensor. The scan motion is provided by means of a scan 
drive and it is suspended on a torsion bar. A high precision angular encoder with corresponding optics generates pulses at $0.008^{\circ}$ of the motion. The earth-pulse width is measured by using the pulses from the encoder. The encoder used in the sensor is based on the Moire fringe technique and is more complex since the scanner motion is sinusoidal unlike in a conical scanner where the speed is uniform. Also, the scanner views two chords of earth by two detectors in the image plane. This is carried out using specially fabricated small bolometers as detectors and low aberration aspheric germanium optics. Such a sensor is planned to be used in the INSAT II series of spacecraft.

3.6b Star sensors: High accuracy attitude determination requires a star sensor rather than an earth sensor due to the inherent limitation of edge sharpness of the IR radiation of earth. A star, being a point source, is very well-defined and serves as an accurate reference. IRS uses a star mapper which maps the sky in an $8^{\circ}$ belt once in every orbital period of 103 minutes. Stars upto the 5 th magnitude are detected and then the position information is passed on to ground which is used for precision attitude determination. The sensor uses catadioptric high speed optics and a 2048 element $\mathrm{CCD}$ detector. The CCD is cooled to $-20^{\circ} \mathrm{C}$ by means of a thermo-electric cooler to reduce the dark current noise of the device. This sensor is novel in concept since it uses a linear array instead of an area array.

3.6c Inertial sensors: Highly accurate measurements of angular rate and angle of spacecraft call for the use of inertial sensors. The inertial sensor measures spacecraft attitude in the inertial frame of reference. It comprises a spinning wheel which maintains its inertial orientation in the absence of applied torques. Spacecraft motion about the gyro's input axes causes the gimbal supporting the spin axis to precess about the output axis. The measured value of the gimbal rotation about its output axis is proportional to the angular displacement of the gyro. A twodegree of freedom dry-tuned gyro has been developed for use in IRS. The gyro uses extremely high precision fabrication techniques and microprocessor-based temperature compensation and rebalancing techniques to avoid drift build-up. However, it needs correction once every few hours to reset the drift error to zero.

In a nutshell, a variety of attitude sensors with different characteristics and levels of accuracies have been developed for ISRO satellite missions.

\subsection{Propulsion system}

Propulsion (Berry 1984) is needed for the orientation (attitude control) and positioning (orbit control) of spacecraft after delivery into its nominal orbit by the launch vehicle.

ISRO has developed/under development four types of propulsion systems. The first one involves a simple cold gas system. The second uses a hybrid system of solid and liquid rockets. The third type employs monopropellant hydrazine, whereas the fourth is a unified propulsion system using fuel (monomethyl hydrazine) and oxidizer $\left(\mathrm{N}_{2} \mathrm{O}_{4}\right)$. This is depicted in figure 8 .

Aryabhata used a propulsion system that spun up the satellite to 90 r.p.m. by expelling dry air through two nozzles in a single shot blow-down mode by opening a single gas bottle containing $1 \mathrm{~kg}$ of dry air. Six gas bottles with a total fuel mass of 


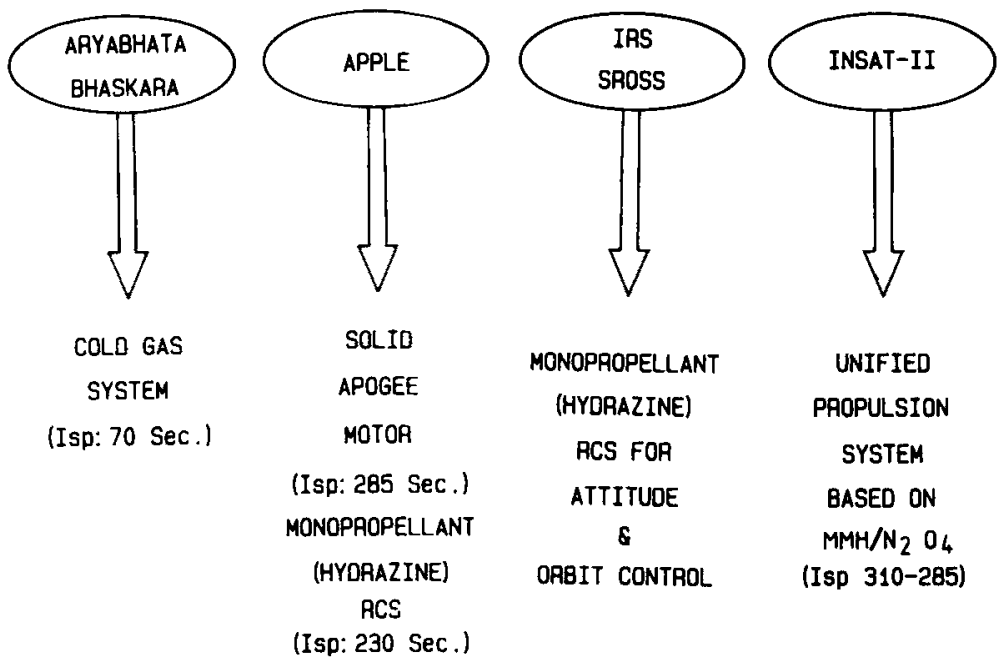

Figure 8. Propulsion technologies for ISRO spacecraft.

$6 \mathrm{~kg}$ were provided. Bhaskara went for a higher level of sophistication using essentially the same hardware as Aryabhata but providing for intermittent spin-rate and spin-axis control. APPLE used two types of propulsion systems, a solid propellant motor for apogee boost operations and a hydrazine monopropellant RCS system for transfer orbit attitude control, 3-axis attitude acquisition, on-orbit roll/yaw control, momentum dumping and station keeping.

Figure 9a shows a schematic of the monopropellant hydrazine propulsion system used in IRS. Monopropellant hydrazine systems derive their energy (typically their fuel having a specific impulse of $230 \mathrm{~s}$ ) from the thermal decomposition of hydrazine $\left(\mathrm{N}_{2} \mathrm{H}_{4}\right)$, a liquid propellant. The decomposed hot gaseous products (nitrogen, and ammonia) can be expanded in the nozzle of a thruster to convert their thermal energy into the kinetic energy of the exhaust stream. $\mathrm{N}_{2} \mathrm{H}_{4}$ contained in tanks is fed under pressure to the engine through electrically operated, isolating, latching valves. A flow control valve allows propellant flow into the decomposition chamber where it is catalytically decomposed into hot gaseous products to be subsequently expanded through a nozzle. IRS carries $80 \mathrm{~kg}$ of hydrazine propellant for a 3-year operational life.

In the development of hydrazine-based RCS systems for IRS and SROSS, several elements were involved. These included a thruster engine, storage tanks, a feed system and flow control valves. All these employ a variety of materials like stainless steel (ss 304 series) and titanium alloys involving a variety of fabrication techniques including EDM, vacuum brazing, electron beam welding etc. In addition to these, development and use of propellants, special elastomers and catalysts posed quite a high degree of technological challenge. For example, techniques of loading the catalyst required special pre-conditioning to overcome the problems of reduction in specific surface as well as increase in pore volume and pore radius during extended operations beyond $500^{\circ} \mathrm{C}$.

Further, in the case of development of engines with 1 Newton thrust, realization of injector configuration with the necessary splash plate and diffuser screens called for a high order of skill. The hardware has to successfully withstand repeated 


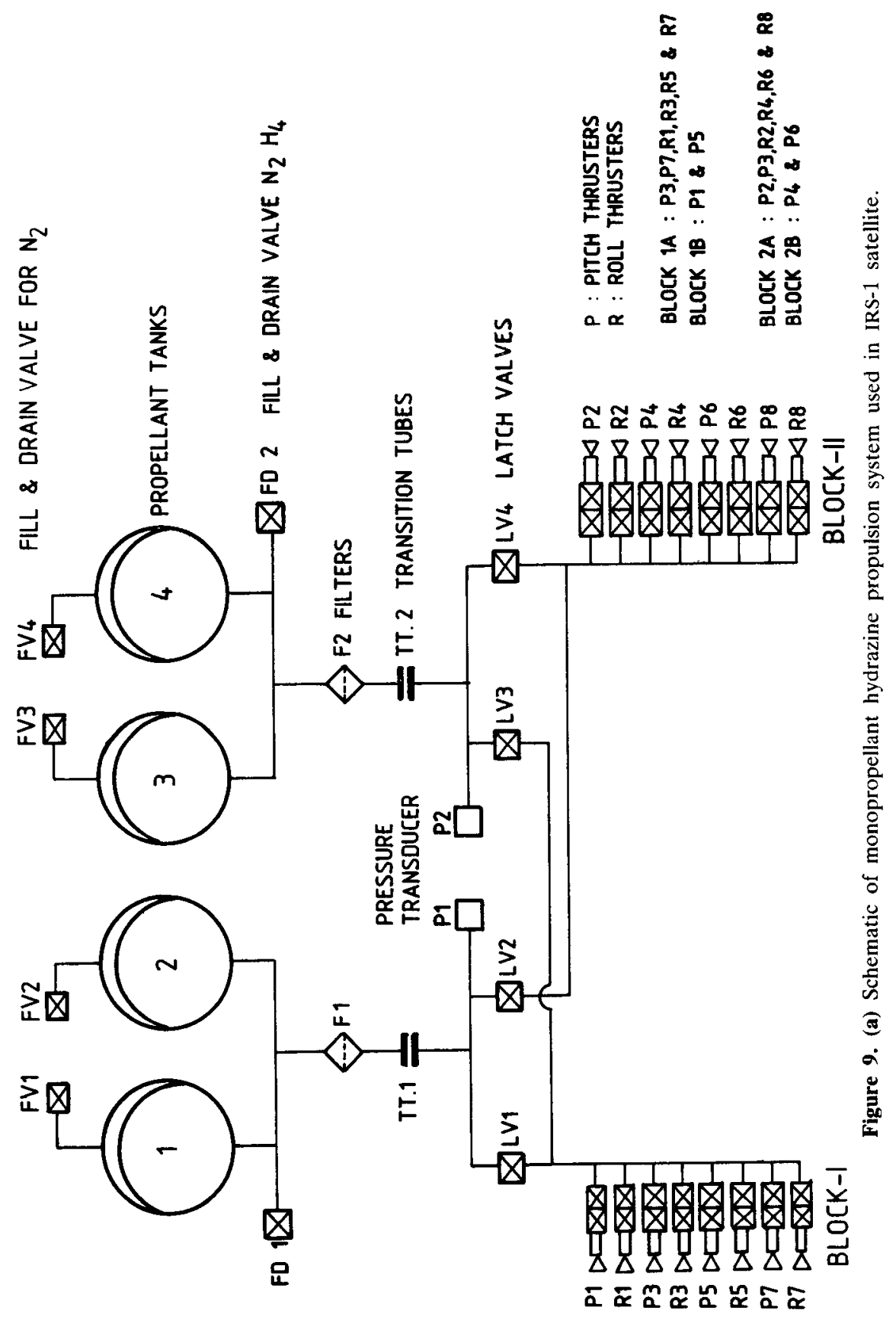



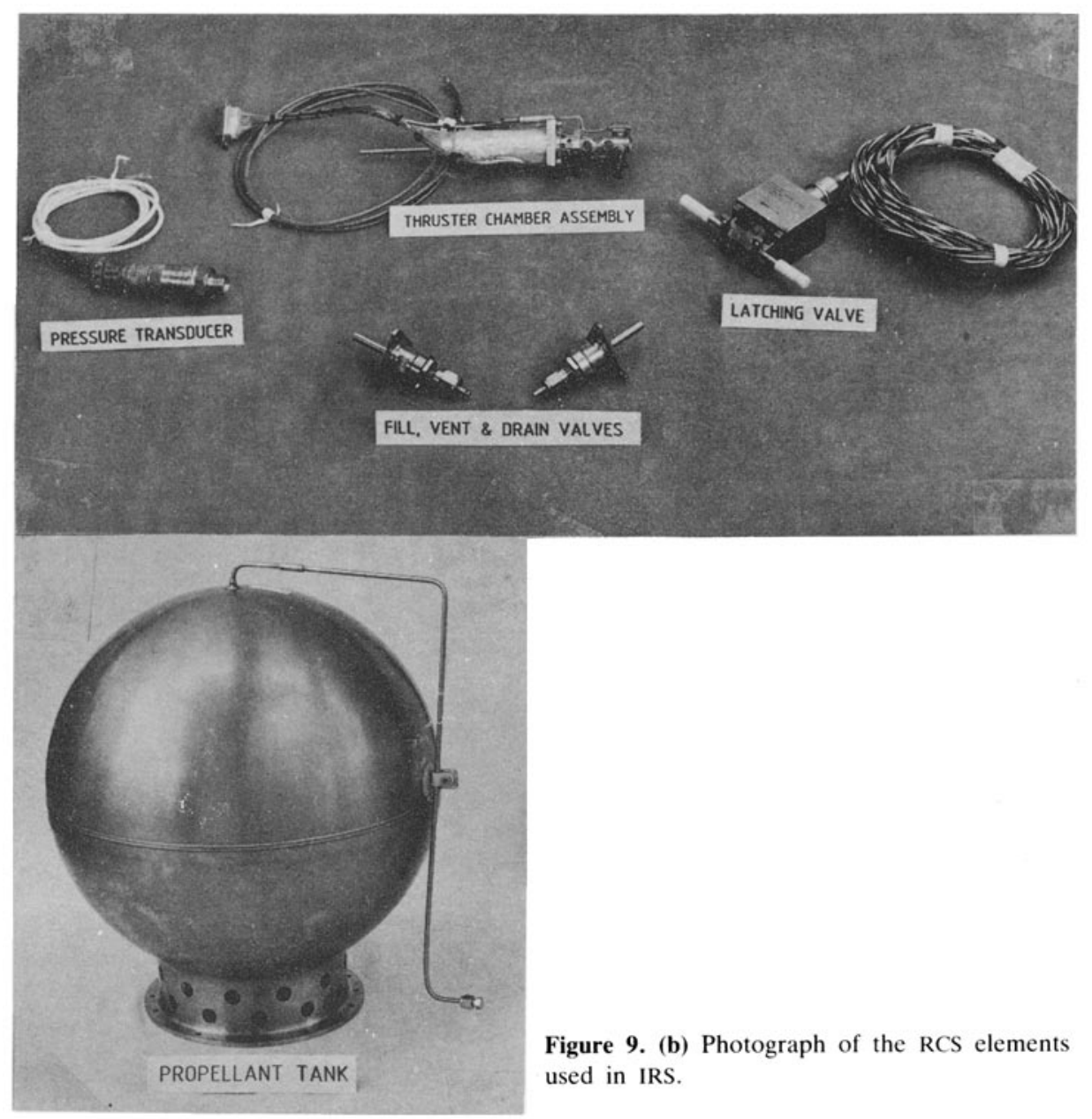

Figure 9. (b) Photograph of the RCS elements used in IRS.

thermal shocks from a number of firing operations that total half a million in a mission life of 3 years. Similarly, the flow control valve which accompanies the thruster calls for highly optimized designs with respect to the power, weight and capability to successfully withstand the corrosive environment of hydrazine over $10^{6}$ operation cycles.

In the case of heavier satellites like the INSAT II series, the propellant requirements are in the range of $850-900 \mathrm{~kg}$ out of a total lift-off mass of around $1850 \mathrm{~kg}$. To reduce the mass of the propulsion system for this class of heavy satellites, a more efficient system is required. It is in this context that $\mathrm{N}_{2} \mathrm{O}_{4}$ and monomethyl hydrazine ( $\mathrm{MMH}$ ) based bipropellant technology is being developed. Such a fuel-oxydizer combination can provide specific impulses in the range of 290-340 s depending on thrust level. This increase in performance over $\mathrm{N}_{2} \mathrm{H}_{4}$ $(230 \mathrm{~s})$ gives substantial mass reduction although it involves significantly increased system complexity. Figure 10 shows a schematic of the propulsion system of INSAT II.

The technology challenges involved in the development of this system are many and varied. Delivery of propellant under zero gravity conditions and against 


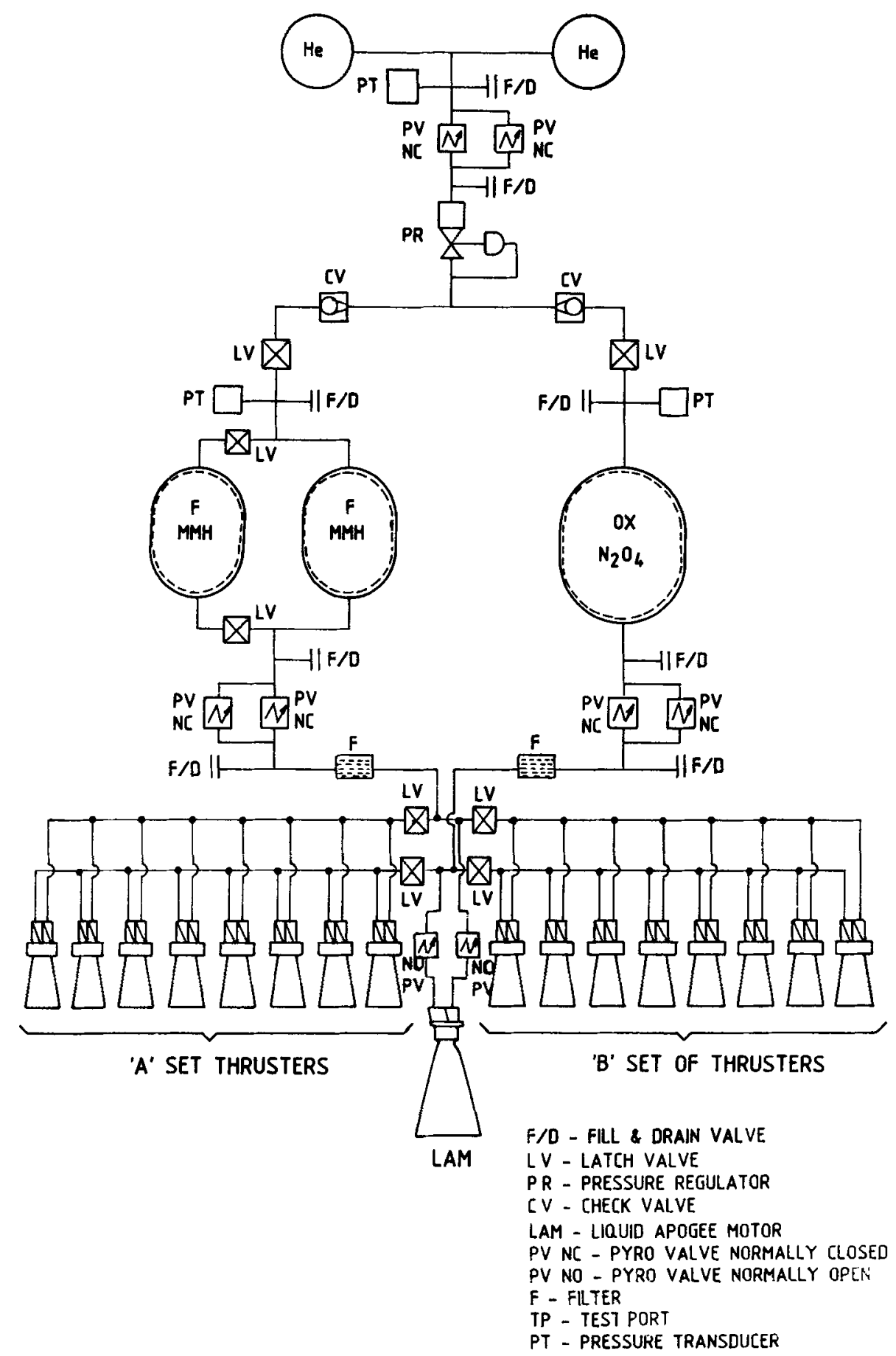

Figure 10. Schematic of unified propulsion system adopted for INSAT II. 
micro-gravity induced by on-board thrusters is one example. Positive expulsion devices like bladders developed for the hydrazine system cannot be effectively utilized for long-life oxidizer systems because of material incompatibility issues. Passive devices for propellant acquisition by surface tension effects and for feeding it on demand, imply a new technology. Fabrication of thin walled Ti-tanks (of $1 \mathrm{~mm}$ wall thickness and $1000-1500 \mathrm{~mm}$ length) is a real challenge in terms of precision machining, vessel cleaning, welding and heat treatment. Storing of corrosive fluids over 7 to 10 years of life without contamination calls for good understanding of corrosion chemistry and the micro-structure of materials. Intense efforts are needed in many directions to (i) understand fluid dynamics behaviour under reduced gravity conditions, (ii) develop devices to acquire the propellant at the outlet, (iii) design systems that are weight-optimized and are easy to test, (iv) understand the propellant reaction on the materials chosen and develop the process accordingly, and (v) develop highly reliable and workable fabrication process and assembly techniques. Design, development and qualification of a $440 \mathrm{~N}$ engine for orbit-raising is another major effort for INSAT II.

Figure 11 shows a summary of the varied technological issues and challenges that are being currently addressed in the development of spacecraft propulsion systems in ISRO.

\subsection{Spacecraft telemetry, tracking and command system}

The telemetry, tracking and command (TTC) system in a space mission performs three primary functions, namely, telemetry, telecommand and tracking. The information gathered from the experiments, various auxiliary on-board instruments as well as from the spacecraft functioning itself is normally processed suitably and

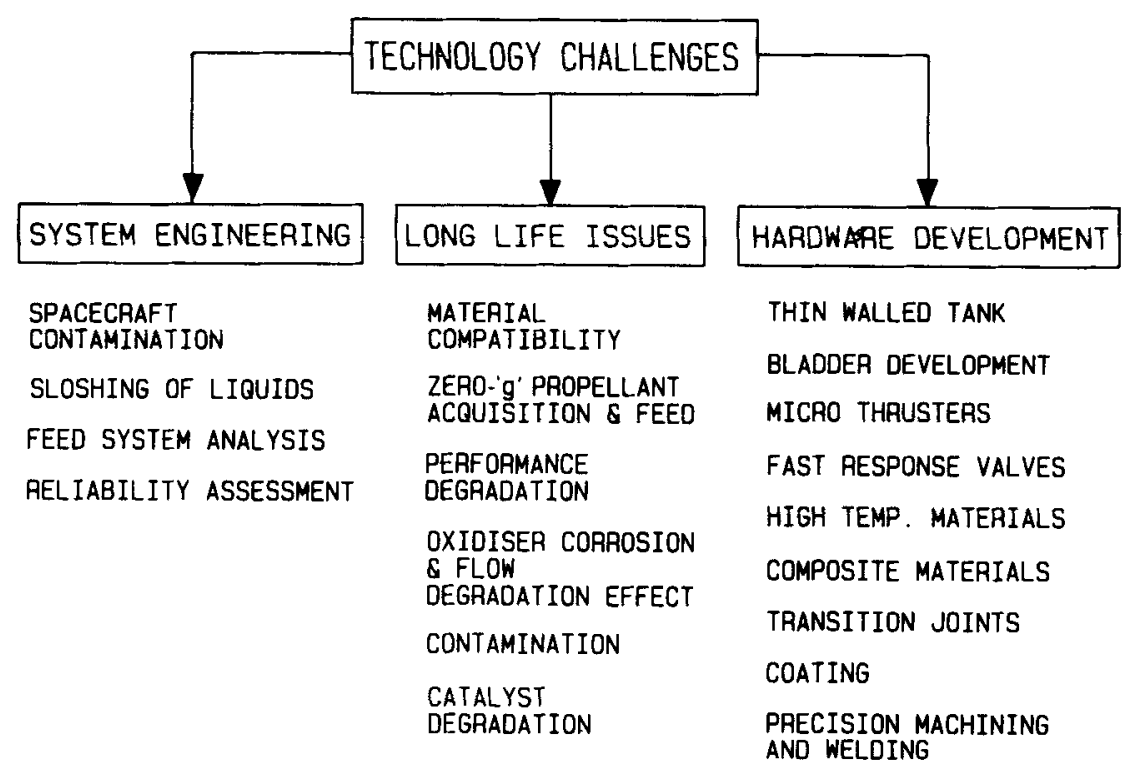

Figure 11. Technological issues and challenges being addressed in spacecraft propulsion systems development. 
transmitted to a ground station via satellite telemetry. The telecommand system enables the exercise of control on the spacecraft from a ground station. Operations such as putting the spacecraft in different functional modes and correcting any in-orbit anomalies are carried out using this system. Determination of the location of the satellite at different times during its orbital motion is made possible by the tracking system. The TTC systems in ISRO spacecraft have evolved from the use of lower frequencies like VHF to those in the $S$ band $(1.55-5.2 \mathrm{GHz})$ to provide for higher accuracies, higher performance standards and for compatibility with international tracking networks. The current systems are also configured to provide for simultaneous commanding and ranging in uplink, and telemetry and ranging in downlink, by providing adequate transponder band-widths and by proper choice of telemetry, command bit rates and subcarrier frequencies to prevent mutual interference in the presence of ranging tones. The need for meeting higher tracking accuracies of about $10 \mathrm{~m}$ in range and $0.1 \mathrm{~m} / \mathrm{s}$ in range rate is achieved through the design of a coherent $S$-band transponder and through the use of higher frequency tones in most recent satellites like the IRS. In order to achieve isotropic response for antenna, null filling antennae are provided in addition to the main antenna both for up and down links.

The telemetry systems used in ISRO spacecraft have evolved technologically in time to provide better reliability, flexibility and growth in performance. The number of channels monitored in spacecraft have risen from 90 in Aryabhata to around 600 in INSAT II (table 3). Current telemetry systems in ISRO spacecraft match the state-of-art through incorporation of multiple format capability to cater to the needs of different phases of the mission, like the satellite acquisition phase, normal operation phase etc., through the use of microprocessors. It also facilitates monitoring at higher sampling rates, any physical parameter on the satellite in the 'dwell' mode. The current systems also incorporate solid state memories in place of on-board tape-recorders to facilitate the recording of satellite health data when the satellite is in regions beyond the visibility of ground stations and to transmit them during subsequent visibility over a ground station.

With the advent of the operational era, ISRO has to develop data-handling systems for high-bit-rate data in the range of several megabits per second from its payloads, such as remote sensing cameras. The designer is faced with the challenge of incorporating appropriate synchronization codes and formatting provisions with the aim of minimizing the loss of data due to bit errors/slippages, and to facilitate identification and retrieval of data from different payload cameras along with auxiliary information to aid data processing. Communication systems in the $X$ band $(5 \cdot 2-10.9 \mathrm{GHz})$ have been developed with quadri phase shift keying (OPSK) modulation schemes for transmitting high data rates $(\sim 25$ million bits per second in the case of IRS-1) in remote sensing satellites like IRS.

The telecommand systems of ISRO spacecraft had to cope not only with growth in the capacity but also with diversity in services. Aryabhata had 35 ON/OFF commands. For IRS spacecraft the command system caters to 385 oN/OFF commands and 21 data commands which offer considerable flexibility in payload operations. The command system also generates commands for placing the spacecraft in the 'safe mode' in case of certain emergencies. Command systems have also been designed to perform certain automatic operations, for example, in the thermal control of the spacecraft. 
Table 3. Growth and evolution of features of telemetry systems

\begin{tabular}{|c|c|c|}
\hline $\begin{array}{l}\text { Name of } \\
\text { satellite }\end{array}$ & $\begin{array}{c}\text { Total number of } \\
\text { channels monitored }\end{array}$ & Salient features \\
\hline Aryabhata & 91 & $\begin{array}{l}\text { Multiplexer (MUX) - analog switches and counter controlled } \\
\text { Analog-digital converter (ADC) - hard-wired } \\
\text { Inputs - unipolar only } \\
\text { Modulation - PCM/FM }\end{array}$ \\
\hline $\begin{array}{l}\text { Bhaskara } \\
\text { I and II }\end{array}$ & 422 & $\begin{array}{l}\text { MUX - 8-channel analog multiplexer devices and counter controlled } \\
\text { ADC - hard-wired } \\
\text { Inputs - unipolar } \\
\text { Modulation - PCM/FM }\end{array}$ \\
\hline APPLE & 374 & $\begin{array}{l}\text { MUX - 8-channel analog MUX devices and counter controlled } \\
\text { ADC - hard-wired } \\
\text { Inputs - unipolar and bipolar } \\
\text { Modulation - PCM/FM } \\
\text { Dwell mode for selected channels }\end{array}$ \\
\hline IRS & 715 & $\begin{array}{l}\text { MUX - 8-channel analog and digital multiplexers and PROM } \\
\text { controlled and distributed in panels } \\
\text { Inputs - unipolar and bipolar } \\
\text { ADC - bipolar module } \\
\text { Modulation - PCM/PSK } \\
\text { Muttiple format and dwell mode for any channel }\end{array}$ \\
\hline SROSS & 325 & $\begin{array}{l}\text { MUX - 8-channel analog and digital multiplexers, controlled by } \\
\text { (i) PROM, (ii) processor } \\
\text { Inputs - unipolar and bipolar } \\
\text { ADC - bipolar module } \\
\text { Modulation - PCM/PSK } \\
\text { Multiple format and dwell facility }\end{array}$ \\
\hline INSAT II & Around 600 & $\begin{array}{l}\text { MUX - 8-channel analog and digital multiplexers and controlled } \\
\text { by processor } \\
\text { Inputs - unipolar and bipolar } \\
\text { ADC - bipolar device } \\
\text { Modulation - PCM/PSK } \\
\text { Dwell of any selected channel }\end{array}$ \\
\hline
\end{tabular}

Some of the future directions for evolution of TTC systems include the development of high-bit-rate PSK modulated command systems, encrypted systems for higher security, internationally compatible packet telemetry and command systems, high gain coding systems incorporating convolutional coding, on-board data compression techniques and on-board fault-tolerant processor systems.

\subsection{Assembly, integration and tests}

The assembly, integration and test (AIT) operation involves integration of various systems in a satellite including its payload and ensuring of proper interfaces among them, both electrically and mechanically. The major tasks in achieving it call for a multi-disciplinary approach and include the design of an optimum layout for the subsystems of the satellite within the weight, volume and access constraints and development of an optimum electrical harness to interconnect the subsystems. Evolution of safe and reliable procedures for handling, assembly, and testing, as 
well as development of hardware to meet the requirements of such procedures, are important functions associated with it. The AIT tasks demand special analytical and engineering skills for measuring and ensuring physical and electrical parameters like inertia, dynamic balance, alignment, electromagnetic compatibility and interface control. Many systems like dynamic balancing machines, centre of gravity and moment of inertia measurement systems have been designed and developed by ISRO to meet the specific requirements for satellites. Specific safety methods have also been evolved for handling and carrying out hazardous operations like fuel filling and pressurisation.

For building up operational grade spacecraft, the bulk of the experience gathered in the experimental Bhaskara and APPLE projects provide the infrastructural base. However, both IRS and INSAT II platforms are more complex and are designed for far more extensive tasks. The complex interplay between the platform subsystems and payloads (high resolution cameras in IRS and a large number of multifunction transponders and VHRR in INSAT II) demand a high degree of interactive design for the configuration layout and also rigorous test plans backed by analysis of in-orbit functional modes. Assembling of large spacecraft with tight control of contamination demand large professional-grade clean rooms and mechanical assembly halls. Simple manual assembly and spacecraft handling techniques cannot cope with the demands of large-sized spacecraft like IRS $(950 \mathrm{~kg})$ and INSAT II $(1850 \mathrm{~kg})$. Mechanisation, automation and built-in safety measures are to be incorporated in the design of handling and integration fixtures.

The second generation INSAT II satellite, for example, presents a higher degree of complexity for system integration. It carries 20 communication and broadcast transponders and a very high resolution radiometer operating in visible and IR bands, designed to serve for seven years. The three-axis stabilized platform fitted with deployable solar panels, solar sail and earth-viewing antennae, with a power generation and dissipation capacity of the order of $1 \mathrm{~kW}$, presents a host of thermal and electromagnetic incompatibility problems. Coupled to this are the configuration constraints that restrict mounting area to $8.2 \mathrm{~m}^{2}$ which is $8 \%$ less than that in INSAT I. Computer-aided approaches for subsystem layout design, electronic housing design, wire routing diagrams, and mass property estimates, become inevitable for handling integration-related problems. Interface data acquisition, control and dissemination also need to be computerised.

Detailed ground checkout procedures are drawn up and a dedicated and fully automated test set-up is configured for the conduct of error-free testing and logging of the results, logical sequencing, simulation of in-orbit functional modes and testing of transfer orbit/on-orbit control loops, during the process of AIT and prior to shipment of spacecraft. For transportation of the current generation spacecraft, a transportation system with a controlled environment is necessary for effective exercise of contamination control and to safeguard against hazards during transit. Similar procedural sequences and ground checkout test plans are drawn up for the operations during the integration of the spacecraft with the launcher as well as just prior to launch.

\section{Reliability and life-time related issues}

In the era of operational satellites, the realization of the highest planned reliability 
levels during the design life times of the satellites is the crucial factor determining the success of a mission. Planned life times for the IRS class of near-earth orbiting satellites are 2-3 years, whereas the corresponding value for the geosynchronous INSAT II class is 7 years. Contrast this with the earlier missions like Aryabhata or Bhaskara, that had planned life times of the order of 1 year and the APPLE communication satellite with its $2 \mathrm{yr}$ life.

Reliability and quality aspects ( $\mathrm{R}$ and $\mathrm{QA}$ ) for ISRO satellites have undergone continuous evolution with the objective of realizing the state-of-art reliability levels. For example, the Bhaskara satellite had an estimated reliability of 0.55 , whereas the reliability goal for INSAT II TS is 0.75 at the end of its $7 \mathrm{yr}$ life. Quality and reliability aspects are brought to bear on several facets of satellite project activity that include choice of proper materials and components, well-defined fabrication methodologies, rigorous test and evaluation plans at subsystem and system levels, as well as carrying out analyses such as fault-free analysis, and failure-mode effect and criticality analysis (FMECA), that could provide valuable inputs to satellite design. Further, conduct of design reviews and instituting mechanisms for analysis, the review and the taking of appropriate corrective measures for problems and failures encountered during the various phases of the development of the satellite, form another important component of quality and reliability efforts.

In earlier experimental satellites like Aryabhata and Bhaskara, in view of the cost and time considerations, coupled with the fact that the goal was to gain experience in different methodologies for carrying out a satellite mission, MIL-STD-883 class of components were used, as also many other non-standard parts and materials. The tests were generally restricted to thermovacuum environments at subsystem and system levels and vibration only for sinusoidal specifications. In the case of APPLE, besides the use of class $S$ radiation hardened components for the first time, solar simulation and thermal balance tests were carried out. Further, in these experimental programmes, FMECA and other reliability related analysis provided only limited inputs during design phase as the related methodologies had to be evolved as part of the programme.

In the current satellite programmes of IRS and INSAT II TS, based on previous experience and taking cognizance of the operational nature of the missions, comprehensive procedures in respect of $\mathrm{R}$ and QA have been drawn up. This is depicted in figure 12. Inputs from R- and QA-related aspects are ensured in all phases of the project, i.e., during the design, development and testing phases. Selection of high-reliability electronic components including screening and upgradation where necessary, use of approved standard materials, introduction of random tests to complement sinusoidal vibration tests at subsystem and system levels, doing acoustic tests at the system level and carrying out solar simulation tests to validate thermal balance aspects of the design at the engineering model level are some of the highlights of the current $R$ and QA efforts in ISRO satellite projects. With the expected commissioning of the $9 \mathrm{~m}$ large space simulation chamber by 1988, solar simulation tests will be extended to flight models of all future IRS and INSAT II satellites.

Another major issue to be reckoned with in long-life satellite missions is the identification of factors that limit the life time, and the evolving of a suitable action plan to cope with the same, through possible solutions to improve the relevant 


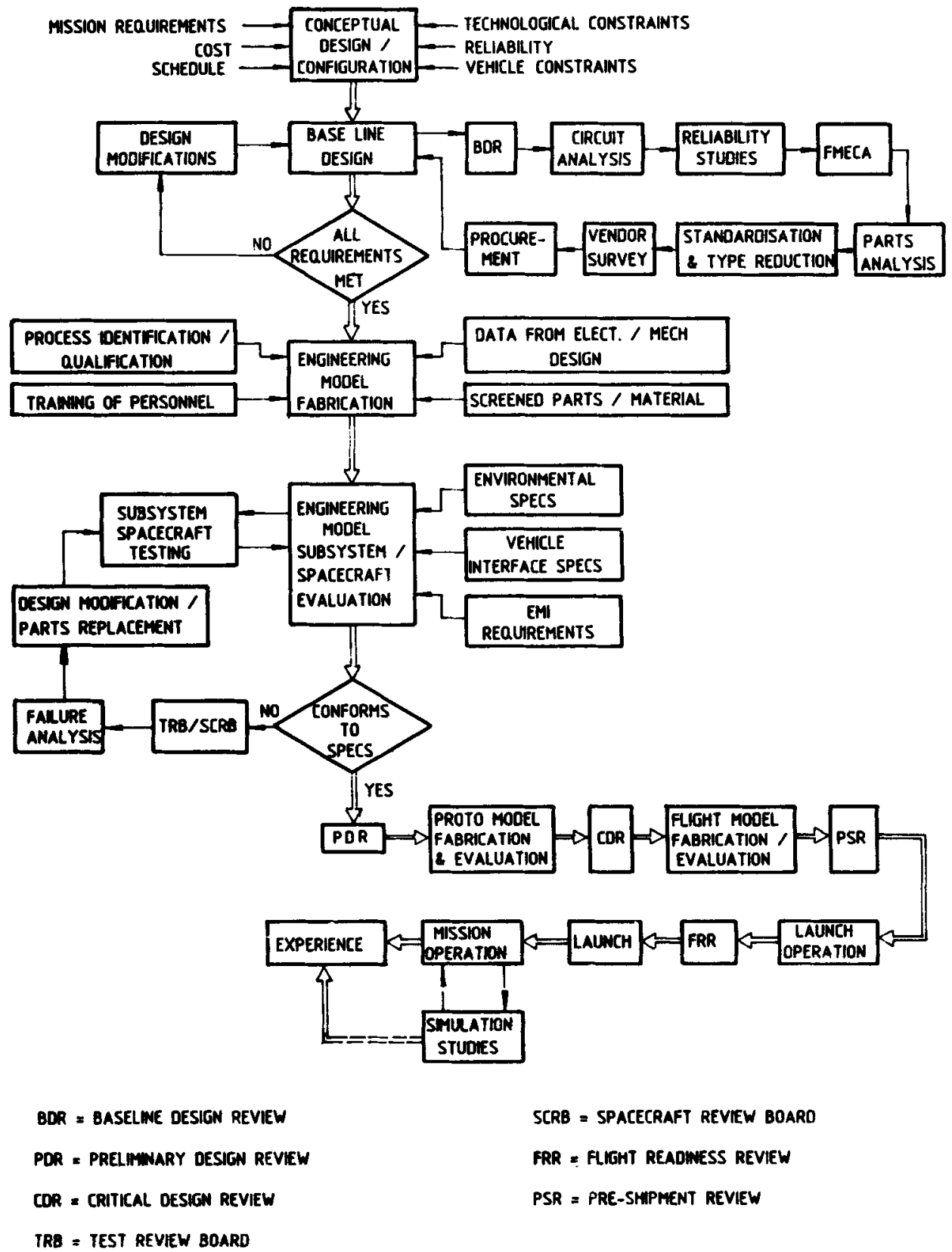

Figure 12. Reliability and quality assurance functions in a spacecraft programme.

critical elements. The main causes of limitations of the satellite life-time are depletion of consumables like the propellant in the RCS system, the slow performance decrease due to wear-out of susceptible parts like lubricated bearings, random or graceful degradation of components, the human error and obsolescence of the mission. Whereas, it is not possible to discuss all the related details in the paper, an idea of the pertinent aspects such as the limiting causes, the subsystems 


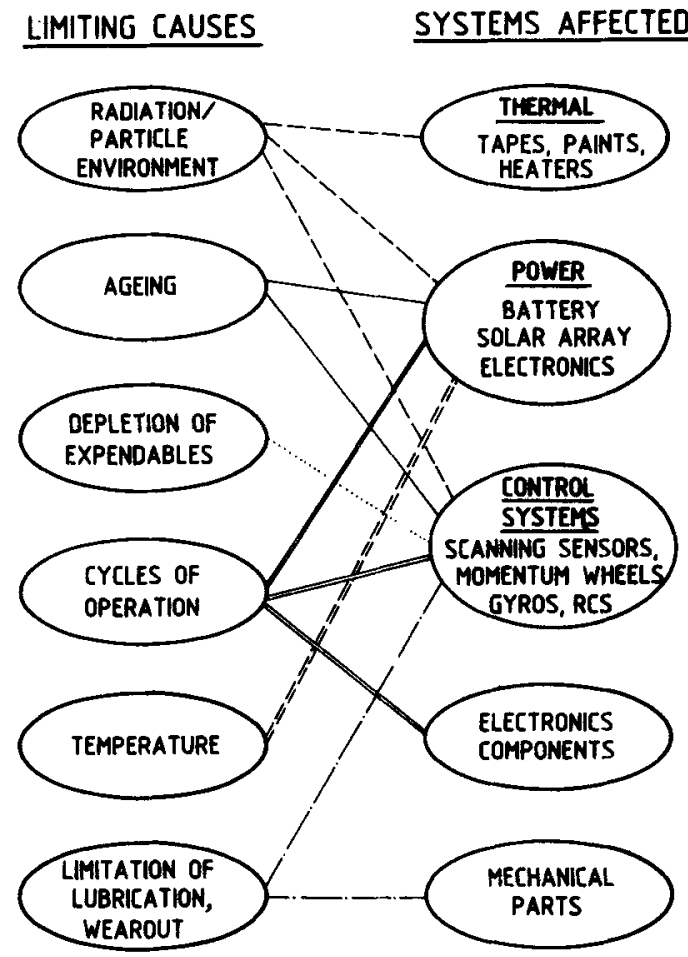

SOLUTIONS

- INCREASE SIZING OF SYSTEMS

- IMPROVEMENT OF PERFORMANCE AND EFFICIENCY

- DEVELOPMENT OF NEW TECHNOLOGIES

- INCREASED REDUNDANCY aND IMPROVEMENT OF RELIABLLITY OF DESIGN

- control of EnVIRONMENT

- extended testing and EVALUATION FOR RELIABLITY ESTABLISHMENT

- RETREIVAL/IN-ORBIT SERVICING

- USE OF ONBOARD INTELLIGENCE FOR MODIFYING/OPTIMISING THEIR ENVIRONMENT

Figure 13. Impact of long life requirement of spacecraft on their technological and systemic aspects.

that get affected by such limiting causes and possible solutions, can be got from figure 13. Suffice it to say that in the developmental plans of IRS and INSAT II satellites, these factors have been carefully addressed and the related action plans have been carefully addressed and the related action plans have been integrated suitably into design, development, qualification and testing phases.

\section{Mission planning and operations}

A space mission as mentioned earlier, encompasses the space, ground, and operational segments. Detailed definition of the mission elements involves translation of the objectives of the mission into space, ground and operational requirements, and integrating them into an operational system to provide the required services to users. This is illustrated as a block schematic in figure 14 wherein the Indian remote sensing satellite mission is taken as an example. Starting from the mission objective of collecting and disseminating space imageries, mission analysis will be carried out to choose the orbit and identify attitude stabilization requirements, the type of launcher, as well as spacecraft power, thermal and control requirements, data transmission system and ground segment, inclusive of mission control and imagery processing. As the next step, the required hardware and software are developed and integrated. The planning includes elements of 


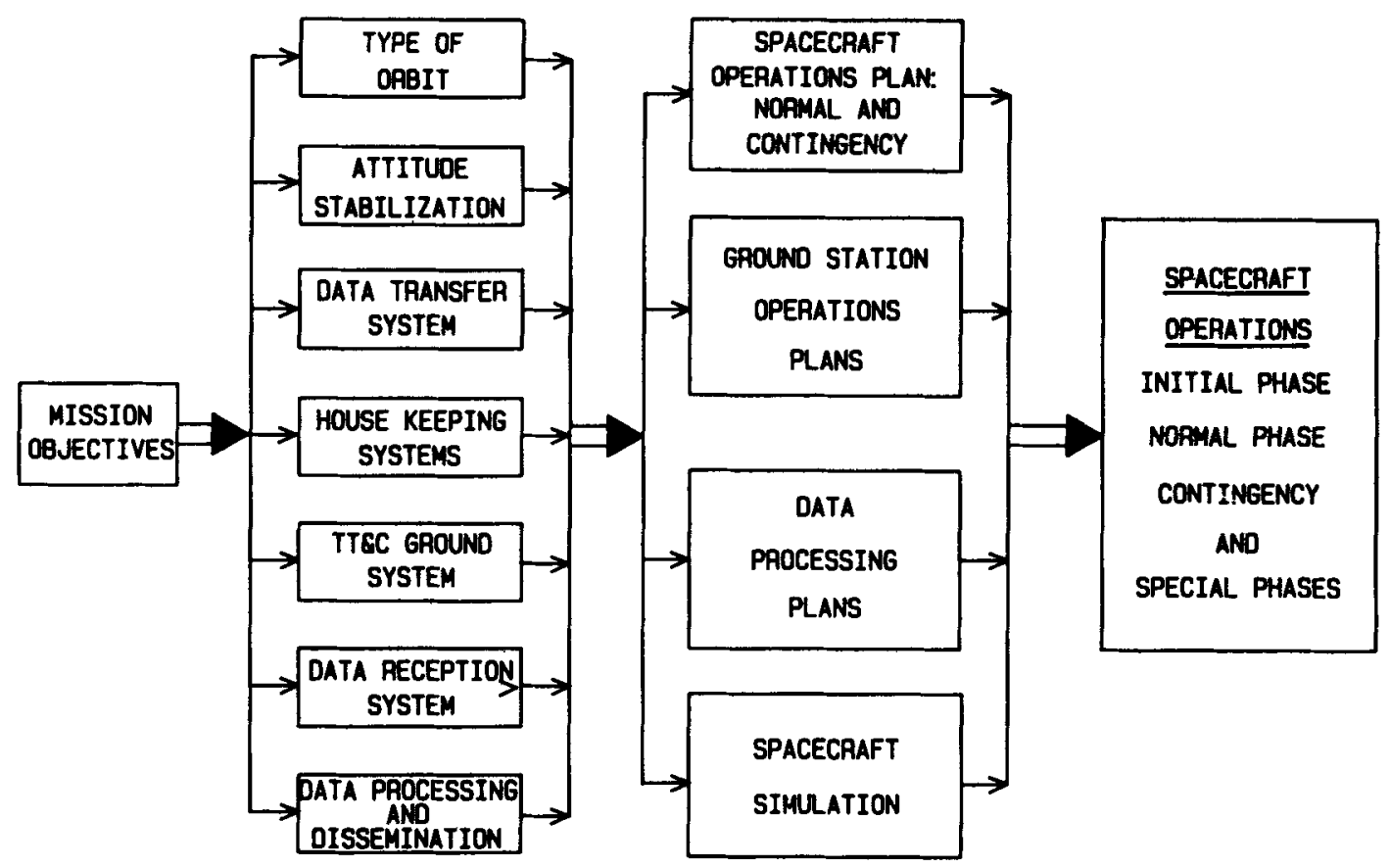

Figure 14. Mission planning and operations sequence.

space and ground systems, operations, data processing and spacecraft simulation. An important element in the link is the simulation. The spacecraft systems will be modelled and simulated on a computer which will be used for training the operators. Finally, all the efforts will culminate in the spacecraft operation once the launch leads to placing the spacecraft in orbit.

\subsection{Earlier experience}

Aryabhata provided ISRO first-hand experience of operating a satellite in orbit including managing contingency simulations. Bhaskara operations were more involved as the requirements included reception of television camera imagery and microwave radiometer data, their processing and dissemination to users. Further, the use of ground-based simulation for understanding in-orbit anomalies was successfully carried out during this mission. This helped in understanding the problem of corona in the TV camera and conclusions drawn from the simulation enabled switching-ON of one of the cameras successfully in Bhaskara I. APPLE provided for the first time, vital experience in the operations related to a geostationary mission. It involved operations in the transfer orbit phase like imparting high spin rates to the spacecraft, orbit-raising to near geosynchronous regime by firing the apogee boost motor, final orbit trimming, solar panel deployment, earth acquisition and three-axis stabilization, and finally normal on-orbit operations. This mission also provided some interesting experience in contingency manoeuvres that included pitch rotation for periodically overcoming the anomalies in thermal behaviour of the satellite. 


\subsection{Operational needs of current satellites}

The operations of satellites like the IRS and INSAT II call for a high order of operational efficiency, and therefore, near-perfect planning to ensure routine user service. A few examples of spacecraft operations should highlight the complex nature of the task.

5.2a IRS operations: The short duration of visibility of near-earth satellites like the IRS, complicates the operations manifold. During the initial phase, a series of complex operations have to be performed on the satellite before it is brought into the safe operational state. Added to this, the satellite experiences eclipse in each orbit resulting in the non-availability of power from its major source, namely, the solar array. Also, the temperature control becomes critical. These operational problems are best illustrated by the example of IRS initial phase operations.

The IRS satellite is placed in orbit with the solar arrays folded, and the battery supplying power to the satellite. To reduce the load on the battery, it is essential to deploy the arrays at the earliest and orient them towards the sun. To achieve this, the satellite itself has to be placed in a fixed attitude mode, viz., the sun-pointing mode. These operations have to be carried out in the very first orbit and within 20 minutes of its injection.

In subsequent orbits, the satellite orientation has to be changed from the sun to the earth whereas the solar arrays continue to track the sun. All these manoeuvres call for extensive data analysis and command control of spacecraft in real-time. It is essential then that a significant part of the operations be automated. One of the most useful features that will be built into the IRS mission is the computerised data analysis, command generation and execution from remote ground stations, through a computer situated at the Mission Control Centre in Bangalore. The remote stations will be linked to the control centre through land/satellite links which will carry information back and forth. The computer at the Control Centre receives telemetry data, analyses it, and displays it on the terminals. It also prompts the spacecraft controller regarding the normal operations to be carried out in terms of command sequence and monitoring parameters. It also identifies abnormal situations and presents recovery procedures to be followed. Achieving such a high degree of sophistication, realizing and operating the system, is in itself a very challenging effort.

To illustrate the complexity of operating the IRS in the normal mode, the following example is useful. The IRS satellite images the earth in strips of $148 \mathrm{~km}$ width during its transit over a ground station in daylight. These strips progressively shift to the west every day and at the end of 22 days, the first strip is imaged again. This is an ideal situation, whereas in practice, the imagery taken on the first day and the 23rd day are slightly displayed due to orbit perturbation. This displacement goes on accumulating if left uncorrected. For the purpose of matching imageries taken on any 22-day cycle, it is specified that the total displacement should be within $\pm 14 \mathrm{kms}$. This calls for accurate determination of orbit, prediction of ground track, determination of required correction, execution of correction, and confirmation of its execution through another orbit determination.

The correction in the semi-major axis would be about $150-200$ m needing a velocity increment of $0.1-0.3 \mathrm{~m} / \mathrm{s}$. Towards this, the semi-major axis has to be determined 
to an accuracy of $20 \mathrm{~m}$ and the eccentricity to an accuracy of $10^{-4}$ degrees. This calls for very precise measurement of satellite range and accurate orbit determination. The range measurement has to be done from two globally separate stations. Finally, the corrections have to be executed at points in the orbit which may or may not be visible to our ground stations. In the latter case, the corrections are done in the programmed mode. Finally, all these operations should be carried out so as to cause no disturbance to normal data collection.

5.2b INSAT II operations: Let us now examine the complexity of INSAT II operations through an illustrative example. Normal communication satellites in geostationary orbit are maintained within $\pm 0 \cdot 1^{\circ}$. The latest trend is to locate two or more satellites within $\pm 0 \cdot 1^{\circ}$ in a cluster to increase the communication channel capacity at a single orbital slot. In the case of INSAT II, it is proposed to co-locate two satellites. This poses a number of complex problems which have to be solved. For example, frequency reuse through orthogonal polarization has to be employed to increase the communication capacity. Apart from other factors, the relative orientation of the on-board antennae on the two satellites affects the isolation between the two orthogonal channels. This depends upon the relative yaw errors of the two satellites which have to be kept as small as possible (less than $0 \cdot 3^{\circ}$ ). As direct yaw measurement throughout the orbit is necessary, it is essential to depend upon gyros. This requires regular calibration and update of the gyros to achieve high accuracy yaw maintenance. Another problem is that when two satellites are co-located, if one of them loses its attitude stabilization, there exists a danger of RF interference in the two TTC channels which may be using at least one frequency in common. Additionally, the attitude-holding thruster firing may not impart pure rotational motion and this results in orbit drift. In such a case, the satellite may interfere with the normal co-located satellite. Careful data analysis and control operations are necessary to handle such delicate situations. The third and most important problem is station keeping. The position of a satellite in orbit is perturbed because of external forces. It experiences a north-south and east-west motion. The east-west motion has two components, one of them being due to eccentricity (this motion is diurnal). For effective co-location, the satellites have to be kept in station, and their daily motion kept in phase. For example, an eccentricity of $10^{-4}$ degree causes a diurnal oscillation of $\pm 0 \cdot 36^{\circ}$. It is evident then that this motion has to be in phase for all satellites of the cluster. This requires that not only the magnitude but also the phase of the eccentricity vector has to be maintained. This is quite a complex challenge to be met by an operations engineer.

\section{In-orbit anomalies and lessons learnt}

During the in-orbit phase, many of the ISRO satellites experienced anomalies that were studied through suitable ground simulations, circumvented by appropriate contingency plans and the lessons learnt were incorporated into subsequent satellites.

In the case of Aryabhata, absence of redundancy to take care of single point failures in the power system resulted in the switch-OFF of the scientific experiments 
on the third day in orbit when the $+9 \mathrm{~V}$ supply failed. All the subsequent ISRO satellites are protected against single point failures of the mainframe systems.

TV camera systems on-board Bhaskara-I experienced anomalous behaviour in the early phase of the mission. The anomalies included premature shut-off of the TV heaters followed by large scale disturbances in the spacecraft status as monitored through telemetry parameters. A three-pronged approach was adopted to study this anomaly that included ground simulations using the simulation model of the spacecraft, evaluation of the payload performance in a thermovacuum environment over long durations and controlled experiments of the high voltage arcing phenomenon in the laboratory. These simulations strongly pointed to the possibility of a corona on-board resulting from high voltage DC/DC converters used for supplying 6 and $8 \mathrm{kV}$ to the cathode and the grid, respectively, of the TV tube. Further, more detailed studies related to the corona occurrence under various pressure and temperature conditions led to the conclusion that such an arcing phenomenon will be most intense in the 250 to 100 torr region for high voltage in the regime of 6 to $8 \mathrm{kV}$. It was also concluded that a slow leakage of the trapped gases from the region of the corona in the payload, aided by thermal cycling effects could lead to a pressure regime below 100 torr when the payload can be switched ON safely. This conclusion was fully validated by the subsequent successful switch ON of one of the cameras a year after the launch. Studies in respect of these anomalies provided valuable inputs in respect of circuitry design involving the use of CMOS devices, material compatibility issues, especially in the presence of thermal cycling effects, and test philosophy for systems using high voltages.

In the case of APPLE, one of the major anomalies was the nondeployment of the north side solar panel. This anomaly, together with the constraints in thermal design that called for meeting the conflicting requirements of thermal control for transfer orbit and on-orbit phases, resulted in certain in-orbit thermal management problems for the satellite. The problem resulted in increased temperatures for systems such as the static horizon sensor or the battery thereby endangering their reliability. This problem was successfully overcome by a method called pitch rotation. It involved rotating the spacecraft around the pitch axis, at a slow rotation of about one rotation per hour, for a few hours around the period of anticipated peak temperature during the waning phase of the eclipse. The lessons learnt from APPLE aided in the generation of exhaustive qualification, testing, assembly and inspection procedures for the mechanisms that have been fully implemented in IRS and SROSS projects. Further, based on the experiences of APPLE, subsequent projects have taken note of possible failure modes, such as non-deployment of solar panels on one side of the spacecraft, by addressing the same at the design phase itself. For example, the IRS design provides for thermal and power management contingencies if solar panels on one side fail to deploy.

The above examples serve to illustrate how some of the in-orbit anomalies of the earlier ISRO satellites provided valuable inputs in the planning and implementation of the current satellites such as IRS and INSAT towards more reliable operation.

\section{Cost and schedule performance}

Any paper that deals with the evolution or assessment of technology development is not complete without touching upon the aspects related to cost and schedule 
performance. The question seminal to such an evaluation is whether the development of a system/subsystem incorporating certain levels of new technology is accomplished in the most cost-effective way. This in turn calls for a reliable scientific method or a standard to compare with. Development of standards on a scientific basis for the evaluation of cost and schedule performance of a satellite project or its subsystem development activity is known to pose enormous limitations owing to uncertainties inherent in developmental activities and also the complex human resource interactions that are difficult to model. Even those few econometric and heuristic models that are developed in the US and in Europe, making use of considerable historical databases, do not yield results that are adequate for use as standards in their own countries. In the light of these, a reasonable method for such assessment could be through a comparison of cost and schedule performances between comparable systems developed in India and abroad. With reasonable assumptions relating to amortisation and development costs and accounting for all direct labour, material and infrastructure overheads including G\&A overheads, the near-operational/operational class of the spacecraft developed in India are realized at a cost $10-20 \%$ lower than that of similar/same type of satellites abroad.

In terms of schedule management, the lead times for satellite development in ISRO is comparable to those abroad, taking into account the fact that a significant portion of lead time in the Indian case (about 20\%) is in fact devoted to incremental infrastructure development for specific missions. Unlike the advanced countries, where the Industry has most of the infrastructure readily available, ISRO has to cope with development of specialized infrastructure through in-house activity as they are not readily available in Indian industry. Taking this into account, a normal lead time of 5 to 7 years for development of a new spacecraft bus is involved in ISRO. This is reduced to about 2 to 3 years depending upon payload complexity wherever an already proven bus is utilized. This situation is comparable to that achieved in other countries where significant advantage exists in terms of industrial $R \& D$ and production capability in aerospace products.

\section{Concluding remarks}

In this paper, we have essentially attempted to present spacecraft technology evolution in ISRO as traced through its different satellite missions, both past and current ones. The technology challenges faced in designing and building the current generation of operational satellites like IRS and INSAT II are specially highlighted. The paper is not meant to be a tutorial in satellite design and fabrication. As such, the related considerations in system and subsystem descriptions are limited only to those details that are pertinent to providing a cogent picture of the technology evolution and the associated challenges. Further, several additional aspects of a space mission like telemetry, tracking and command networks, spacecraft control centre, detailed methodologies for in-orbit management of satellites, data reception and processing related to ground systems for remote sensing satellites etc. have been dealt with, at best peripherally.

Other important elements not covered in this paper are the management systems set up for the execution of satellite missions. One of the greatest challenges faced in 
the evolution of space activities in the country perhaps was in the development of suitable organization and management systems conducive for conduct of timebound high technology projects. Many new organizational systems and methods have been conceived, experimented with and tested just like a host of technologies that were developed for space projects. Since a separate article (Rajan 1987) elsewhere in this issue deals with the management systems, the related details are not elaborated in this paper.

Establishment of a firm and durable base for indigenous capabilities in satellite technology is but one major aspect of a multi-faceted and multi-dimensional program relating to space that Prof. S Dhawan guided and nurtured over a period of twelve years. As part of his pioneering efforts in bringing the benefits of space for improving the basic quality of life of the people of India, a major thrust was given to space applications that included communications, natural resources survey, and meteorology. He also provided necessary support and encouragement to the space scientists so that they could undertake the planning and conduct of front ranking experiments in astronomy, aeronomy, and other areas of space sciences. To ensure the continuity of such efforts, he saw the need for establishing a strong indigenous base in space technology encompassing both launch vehicles and satellites. Before he relinquished the Chairmanship of ISRO, he saw to it that the necessary institutions for this purpose were built both inside and outside ISRO and their working culture was made conducive to the rèalization of such high technology systems in a time-bound fashion.

It is a matter of great privilege for the authors to write an article on ISRO satellite technology for inclusion in this volume being brought out in honour of Prof. $S$ Dhawan and we would like to thank Prof. R Narasimha and Dr A P J Abdul Kalam for it. The authors would like to record their indebtedness to Prof. U R Rao whose direction and encouragement were primarily responsible for the various developments reported in this paper. The interest shown by Col. $\mathbf{N}$ Pant while writing this paper is also gratefully acknowledged.

Several colleagues in ISRO assisted in the preparation of this article. While it is difficult to thank each one of them individually, we would like to make a special mention of M S S Prabhu, C V R Reddy, H Narayana Murthy, B L Agrawal, S Pal, Y K Singhal, P Kudva, P S Goel, Y K Jain, K Anantharam, K L Valliappan, V R Katti and Y N Bhushan.

\section{References}

Adams I L 1966 Space Technology - spacecraft mechanical engineering, NASA SP-66 Berry W 1984 ESA Bull. 40: 6-24

Dhawan S, Singh J P, Kale P P 1979 IEEE Trans. Broadcast. BC-25: 121-127

Kasturirangan K 1985 Int. J. Remote Sensing 6: 387-400

Navalgund R R, Kasturirangan K 1983 Proc. Indian Acad. Sci. (Eng. Sci.) 6: 313-336

Rajan Y S 1987 this volume, pp. 397-413

Rao U R, Kasturirangan K 1979 The Aryabhata Project (Bangalore: Indian Acad. Sci.)

Rao U R, Kasturirangan K, Jayaraman V $1982 \mathrm{~J}$. Aeronaut Soc India 34: 67-76

Rao U R, Pant N, Kale P P, Narayanan K, Singh J P 1987 The Indian National Satellite System, Space Commun. Broadcast. (accepted) 
Rao U R, Ramachandran P 1987 Second generation Indian National Satellite System Space Segment INSAT II, International Astronautical Federation (IAF) Congress, Brighton, UK

Scull J R 1966 Space Technology - spacecraft guidance and control, NASA SP-68

Singer F (ed.) 1964 Torques and attitude sensing in earth satellite (New York: Academic Press)

Vasagam R M, Shrivastava S K 1983 J. Aeronaut. Soc. India 35: 133-276 